FY 2006

\title{
MODELING RELUCTANCE-ASSISTED PM MOTORS
}

Prepared by:

Oak Ridge National Laboratory

Mitch Olszewski, Program Manager

\section{Submitted to:}

Energy Efficiency and Renewable Energy

FreedomCAR and Vehicle Technologies

Vehicle Systems Team

Susan A. Rogers, Technology Development Manager

January 2006 
NATIONAL LABORATORY

MANAGED BY UT-BATTELLE

FOR THE DEPARTMENT OF ENERGY

\section{Engineering Science and Technology Division}

\section{Modeling Reluctance-Assisted PM Motors}

\author{
P. J. Otaduy
}

J. W. McKeever

Publication Date: January 2006

Prepared by the

OAK RIDGE NATIONAL LABORATORY

Oak Ridge, Tennessee 37831 managed by

UT-BATTELLE, LLC for the

U.S. DEPARTMENT OF ENERGY Under contract DE-AC05-00OR22725 


\section{DOCUMENT AVAILABILITY}

Reports produced after January 1, 1996, are generally available free via the U.S. Department of Energy (DOE) Information Bridge:

Web site: http://www.osti.gov/bridge

Reports produced before January 1, 1996, may be purchased by members of the public from the following source:

National Technical Information Service

5285 Port Royal Road

Springfield, VA 22161

Telephone: 703-605-6000 (1-800-553-6847)

TDD: $703-487-4639$

Fax: 703-605-6900

E-mail: info@ntis.fedworld.gov

Web site: http://www.ntis.gov/support/ordernowabout.htm

Reports are available to DOE employees, DOE contractors, Energy Technology Data Exchange (ETDE) representatives, and International Nuclear Information System (INIS) representatives from the following source:

Office of Scientific and Technical Information

P.O. Box 62

Oak Ridge, TN 37831

Telephone: 865-576-8401

Fax: 865-576-5728

E-mail: reports@adonis.osti.gov

Web site: http://www.osti.gov/contact.html

This report was prepared as an account of work sponsored by an agency of the United States Government. Neither the United States government nor any agency thereof, nor any of their employees, makes any warranty, express or implied, or assumes any legal liability or responsibility for the accuracy, completeness, or usefulness of any information, apparatus, product, or process disclosed, or represents that its use would not infringe privately owned rights. Reference herein to any specific commercial product, process, or service by trade name, trademark, manufacturer, or otherwise, does not necessarily constitute or imply its endorsement, recommendation, or favoring by the United States Government or any agency thereof. The views and opinions of authors expressed herein do not necessarily state or reflect those of the United States Government or any agency thereof. 


\section{CONTENTS}

Page

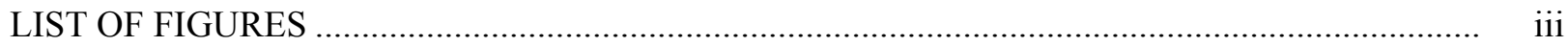

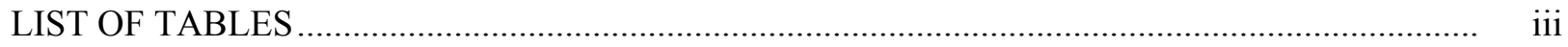

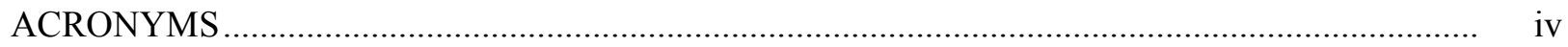

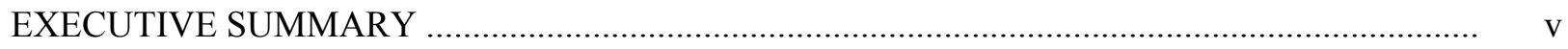

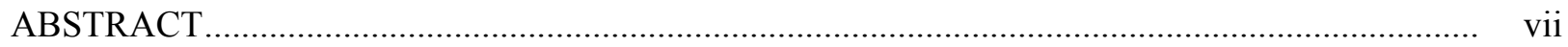

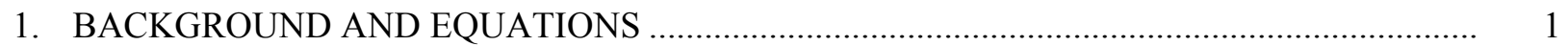

1.1 RELUCTANCE CONTRIBUTION TO TORQUE ........................................................... 1

1.2 DESIGN EQUATIONS OF A SYNCHRONOUS PM MOTOR WITH

SALIENCY RATIO ABOVE ONE ................................................................................ 2

1.3 EQUIVALENT CIRCUITS FOR DYNAMIC OPERATION IN THE SYNCHRONOUSLY-ROTATING ROTOR FRAME........................................................ 7

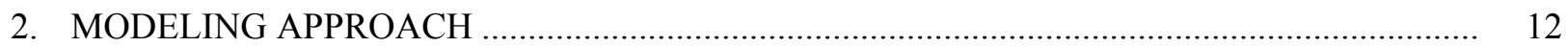

2.1 TERMINAL VOLTAGE UNDER CURRENT-PHASE ANGLE CONTROL ..................... 13

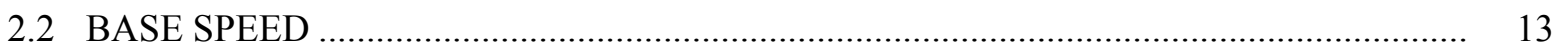

2.3 ATTAINABLE CURRENT UNDER CURRENT-PHASE ANGLE OR UNDER VOLTAGE-PHASE ANGLE CONTROL IN THE VOLTAGE-LIMITED REGION ......... 14

2.4 APPLICATION OF MOTOR X PARAMETERS TO VOLTAGE AND CURRENT EXPRESSIONS

25 POWER EXPRESSION USED FOR OPTIMIZATION 18

2.6 NUMERICALLY DETERMINED MAXIMUM-POWER DELIVERY UNDER VOLTAGE CONTROL IN THE VOLTAGE-LIMITED REGION ................................... 19

2.7 A MORE TRACTABLE RELATION FOR MAXIMUM POWER UNDER CURRENT CONTROL IN THE CURRENT-LIMITED REGION ..................................................... 21

3. MAXIMIZING PERFORMANCE OF A MOTOR WITH SALIENCY:

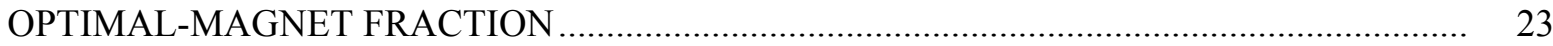

3.1 OPTIMAL-MAGNET FRACTION BASED ON STEADY-STATE CALCULATIONS .... 28

3.2 OPTIMIZATION CONSIDERING ACTUAL LIFETIME OPERATING CYCLES ........... 31

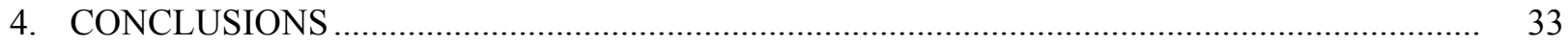

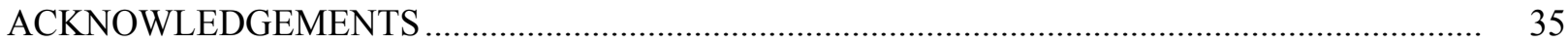

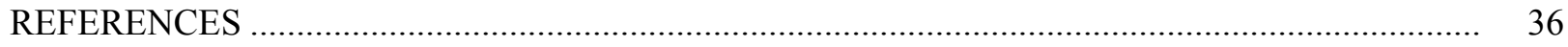

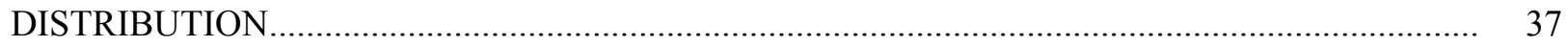




\section{LIST OF FIGURES}

Figure

Page

1 Magnet torque and total-shaft torque of a four-pole inset reluctance-assisted PM motor

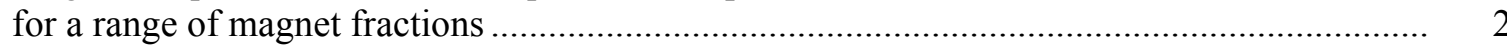

2 Two possible configurations of an inset PM motor ........................................................ 2

3 Equivalent d-q circuits of a synchronous motor in the synchronously-rotating reference frame

4 Phasor diagram of the d- and q-axes of a PM motor employing flux weakening ( $\mathrm{I}_{\mathrm{d}}$ in the second quadrant)

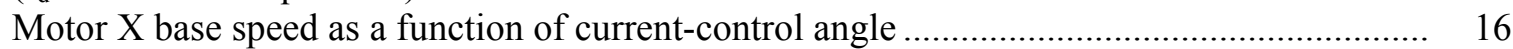

$6 \quad$ Motor $X$ with voltage-limited attainable current under $\gamma$ control ............................................ 17

$7 \quad$ Motor X with voltage-limited attainable current under $\beta$ control............................................. 18

8 Power output as a function of speed for the full range of voltage-control angles for Motor X.

9 Optimal-power output as a function of speed for Motor X.

10 Voltage-phase angle, $\beta$, required to obtain maximum-power output above base speed as a function of speed for Motor X....

11 Maximum-power output in the current-limited region below base speed for Motor X

12 Maximum-power output trajectories below base speed in the current-limited region for Motor X-like motors with saliencies from one to four

13 Dependence of the fundamental parameters on the magnet's angular pitch.

14 Dependence of performance on the magnet's strength for $170^{\circ} \mathrm{PM}$ pitch....

15 Zoom-in of Fig. 14...

16 Speed dependence of optimal performance on the PM pitch angle at $100 \%$ magnet strength.

17 Zoom-in of Fig. 16.

18 Speed dependence of optimal performance on the magnet's strength for a $130^{\circ}$ PM pitch angle 2 2

(1)

7

8




\section{ACRONYMS}

CPSR

d-axis

emf

FHDS

FUDS

HEV

IPM

$\mathrm{mmf}$

PM

q-axis

rms

THS

THSII constant power speed ratio direct axis electromotive force Federal Highway Driving Schedule Federal Urban Driving Schedule hybrid electric vehicle internal permanent magnet magneto-motive force permanent magnet quadrature axis root-mean square Toyota Hybrid System Toyota Hybrid System (new generation) 


\section{EXECUTIVE SUMMARY}

Chapter 1 of this report contains a derivation of the fundamental equations used to calculate the base speed, torque delivery, and power output of a reluctance-assisted permanent magnet (PM) motor which has a saliency ratio greater than 1 as a function of its terminal voltage and current, voltage-phase angle, and current-phase angle.

In Chapter 2, the fundamental equations derived in the first chapter are employed to obtain expressions for a motor's terminal voltage, $\mathrm{V}_{\mathrm{t}}\left(\mathrm{I}_{\mathrm{t}}, \omega_{\mathrm{e}}, \gamma\right)$; electrical-base speed, $\omega_{\text {ebase }}\left(\mathrm{V}_{\text {source }}, \mathrm{I}_{\max }, \gamma\right)$; maximumattainable current above base speed (voltage-limited region) when current-phase angle, $\gamma$, is controlled, $\mathrm{I}_{\mathrm{t}}\left(\mathrm{V}_{\text {source }}, \omega_{\mathrm{e}}, \gamma\right)$; and maximum-attainable current above base speed when voltage-phase angle, $\beta$, is controlled, $\mathrm{I}_{\mathrm{t}}\left(\mathrm{V}_{\text {source }}, \omega_{\mathrm{e}}, \beta\right)$. The equations are initially applied to model Motor $\mathrm{X}$ using symbolicallyoriented methods with the computer tool Mathematica to illustrate the functional dependency of base speed, $\omega_{\text {ebase}}$, on $\gamma$. A similar expression for base speed may be derived as $\omega_{\text {ebase }}\left(V_{\text {source }}, I_{\max }, \beta\right)$. Once a base speed is selected, unique values exist for $\gamma$ and $\beta$ which are expressed as $\gamma_{\mathrm{o}}$ and $\beta_{\mathrm{o}}$ for Motor X. Above base speed, the dependencies of $\mathrm{I}_{\mathrm{t}}$ on $\omega_{\mathrm{e}}$ and $\gamma$ and of $\mathrm{I}_{\mathrm{t}}$ on $\omega_{\mathrm{e}}$ and $\beta$ are applied to determine the maximum-attainable currents as a function of speed under $\gamma$ or $\beta$ control, respectively, for $\mathrm{V}_{\mathrm{t}}=\mathrm{V}_{\text {source. }}$. Below base speed, the same dependencies are used to determine the required-terminal voltage for $I_{t}=I_{\max }$ under $\gamma$ or $\beta$ control. The method of maximizing output power above base speed under $\beta$ control is indicated, but because of the nature of the solution of a fourth-order polynomial, the equations are not listed. Instead, the numerical results from the fourth-order equations for power under $\beta$ control are plotted as a function of speed and $\beta$, and the optimal-power trajectory is superimposed on the power surface. This complicated numerical solution is summarized in a plot of maximum power versus speed and a plot of the control angle, $\beta$, required to produce maximum power versus speed. Chapter 2 ends with plots that use the simpler expressions for the optimal-current-phase angle, $\gamma$, and maximum power under $\gamma$ control over the current-limited region below base speed. The plot of maximum power from rest to base speed under current-phase angle control is linear with speed. A second plot shows the current-phase angle versus saliency ratio, and a third plot shows the torque versus saliency ratio which is linear. This last plot quantifies the torque benefit from increasing the saliency ratio of a motor similar to Motor X.

In Chapter 3, the fundamental equations from the first chapter are applied to model an inset PM motor using numerically-oriented methods with the computer tool LabVIEW. The equations are solved iteratively to find optimal current and voltage angles that yield maximum power and maximum efficiency from rest through the current-limited region to base speed and then through the voltage-limited region to high rotational speeds. Currents, voltages, and reluctance factors were all calculated and external loops were added to perform additional optimization with respect to PM pitch angle, which determines the magnet fraction, and with respect to magnet strength.

Chapter 3 begins with curves of magnet-flux linkages $\mathrm{L}_{\mathrm{d}}, \mathrm{L}_{\mathrm{q}}, \mathrm{L}_{\mathrm{q}}-\mathrm{L}_{\mathrm{d}}$, and $\mathrm{L}_{\mathrm{q}} / \mathrm{L}_{\mathrm{d}}$ and characteristic current plotted as a function of PM pitch angle. These curves show that $\mathrm{L}_{\mathrm{q}}-\mathrm{L}_{\mathrm{d}}$ reaches a peak at a PM pitch angle of $90^{\circ}, \mathrm{L}_{\mathrm{q}} / \mathrm{L}_{\mathrm{d}}$ reaches a peak at $130^{\circ}$, and characteristic current reaches a peak at about $160^{\circ}$. Plots from the numerical analysis in Chapter 3 indicate that the optimal-magnet fraction for maximum power delivery is 0.72 which corresponds to a PM pitch of $130^{\circ}$; very close to the value where the saliency ratio peaks but not close to the value where $\mathrm{L}_{\mathrm{q}}-\mathrm{L}_{\mathrm{d}}$ peaks. Further, the strength of Motor $\mathrm{X}$ magnets may be lowered to $80 \%$ of full strength without significantly impacting motor performance for PM pitch angles between peak saliency and peak-characteristic current.

Based on the observations that the optimal-magnet pitch is $130^{\circ}$ which corresponds to a magnet fraction of 0.72 and that the strength of the PM is optimal for $80 \%$ of the original strength, a complete set of curves is presented showing currents, optimal-current-phase angles, terminal voltage, and optimal 
voltage-phase angle as a function of speed for maximum power over a range of strengths. A second set of the same curves follows as a function of speed for $80 \%$ magnet strength over a range of PM pitch angles.

A final discussion of optimization of motor configuration based on actual life-cycle or motor-use curves such as the Federal Urban Driving Cycle and the Federal Highway Driving Cycle completes the chapter. It appears feasible to involve maximizing a driving-cycle-weighted efficiency as a criterion for selecting the final optimal-PM fraction for this inset PM motor. We recommend that this be explored as part of future research because low efficiency at peak torque may be acceptable when there is infrequent call for peak torque. 


\begin{abstract}
This report contains a derivation of the fundamental equations used to calculate the base speed, torque delivery, and power output of a reluctance-assisted PM motor which has a saliency ratio greater than 1 as a function of its terminal voltage, current, voltage-phase angle, and current-phase angle.

The equations are applied to model Motor X using symbolically-oriented methods with the computer tool Mathematica to determine: (1) the values of current-phase angle and voltage-phase angle that are uniquely determined once a base speed has been selected; (2) the attainable current in the voltage-limited region above base speed as a function of terminal voltage, speed, and current-phase angle; (3) the attainable current in the voltage-limited region above base speed as a function of terminal voltage, speed, and voltage-phase angle; (4) the maximum-power output in the voltage-limited region above base speed as a function of speed; (5) the optimal voltage-phase angle in the voltage-limited region above base speed required to obtain maximum-power output; (6) the maximum-power speed curve which was linear from rest to base speed in the current limited region below base speed; (7) the current angle as a function of saliency ratio in the current-limited region below base speed; and (8) the torque as a function of saliency ratio which is almost linear in the current-limited region below base speed.
\end{abstract}

The equations were applied to model Motor X using numerically-oriented methods with the computer tool LabVIEW. The equations were solved iteratively to find optimal current and voltage angles that yield maximum power and maximum efficiency from rest through the current-limited region to base speed and then through the voltage-limited region to high-rotational speeds. Currents, voltages, and reluctance factors were all calculated and external loops were employed to perform additional optimization with respect to PM pitch angle (magnet fraction) and with respect to magnet strength. The conclusion was that the optimal-magnet fraction for Motor X is 0.72 which corresponds to a PM pitch angle of $130^{\circ}$, a value close to the maximum-saliency ratio in a plot of saliency ratio versus PM pitch angle. Further, the strength of Motor X magnets may be lowered to $80 \%$ of full strength without significantly impacting motor performance for PM pitch angles between the peak saliency $\left(130^{\circ}\right)$ and peak-characteristic current $\left(160^{\circ}\right)$.

It is recommended that future research involve maximizing a driving-cycle-weighted efficiency based on the Federal Urban Driving Cycle and the Federal Highway Driving Cycle as criteria for selecting the final optimal-PM fraction and magnet strength for this inset PM motor.

Results of this study indicate that the reduction in PM torque due to reduced-magnet fraction will be more than compensated by the reluctance torque resulting from the higher saliency ratio. It seems likely that the best overall performance will require saliency; consequently, we think the best motor will be a reluctance-assisted PM motor. This should be explored for use with other types of PM motors, such as fractional-slot motors with concentrated windings. 


\section{BACKGROUND AND EQUATIONS}

The importance of reluctance torque has recently been recognized [1] and commercially exploited by the automotive community. The outstanding example is the internal permanent magnet (IPM) motors developed by Toyota to drive their Toyota Hybrid System (THS) and Toyota Hybrid System-new generation (THSII) hybrid electric Prius models [2]. Reluctance torque, which will be explained in this report, occurs when there is a difference between stator-reaction inductance referenced to the center, direct axis (d-axis), of a rotor's permanent magnet (PM) and the stator inductance referenced to the midpoint in the space separating a PM from its closest PM neighbor with opposite polarity, quadrature axis (q-axis). Such a difference does not occur in rotors with surface mounted PMs because of the uniform permeability of the materials in the rotor's structure; however, the difference in inductances may be significant for IPMs. The ratio of the largest inductance (along q-axis) to the smallest inductance (along d-axis) is known as the saliency ratio. When designing IPMs, the objective is to maximize the saliency ratio while matching the reluctance torque it produces with the PM torque.

There are several types of IPM motors. One of the most prominent is the inset PM motor which is similar to a surface-mounted PM motor, except that the magnets are embedded in the rotor-silicon steel making their surface flush with the rotor surface and the magnets are separated by a width of silicon steel. The ratio of the angle subtended by the magnet to the angle subtended by one pole is the magnet fraction. Developing a methodology to determine the magnet fraction that produces the best motor performance is the subject of this report. Part of the development of the methodology is the determination of the meaning of best performance.

Several questions are addressed in this report related to the importance of reluctance in PM motors:

1. How does reluctance torque improve the performance in a reluctance-assisted PM motor?

2. What can a reluctance-assisted PM motor do that a PM motor cannot do by itself?

3. What are the equations used to model the reluctance-assisted PM motor?

4. How are the effects of magnetic saturation modeled for a reluctance-assisted PM motor?

5. What is the criterion that should be used to define optimum performance?

6. Once optimum performance is defined, how is the optimum-magnet fraction determined?

\subsection{RELUCTANCE CONTRIBUTION TO TORQUE}

This task was initiated because of Fig. 1 which was calculated using SPEED software [3]. Figure 1 is a plot of the sum of reluctance torque and PM torque shown in red for a four-pole motor as the magnet fraction is varied from 0 ( 0 electrical degrees) as shown in Fig. 2(a) to 1 (180 electrical degrees) as shown in Fig. 2(b). Since the PM torque is shown in green, the distance between the red and green curves is the reluctance torque. Figure 1 shows that the total torque passes through a maximum at a magnet fraction of about $1 / 2$ suggesting that there is a magnet fraction at which the torque is optimum. Furthermore, at that point there is a significant increase in the torque above that produced by the magnets alone. This task was to examine the equations used to design IPMs and to determine the optimal-magnet fraction. At the onset of this task, we thought the primary benefit of a reluctance-assisted PM motor is that it can achieve a required torque with less magnet material, which would allow it to operate at higher constant power speed ratio (CPSR). Alternately, it can achieve a higher torque than a surface-mounted PM motor. 


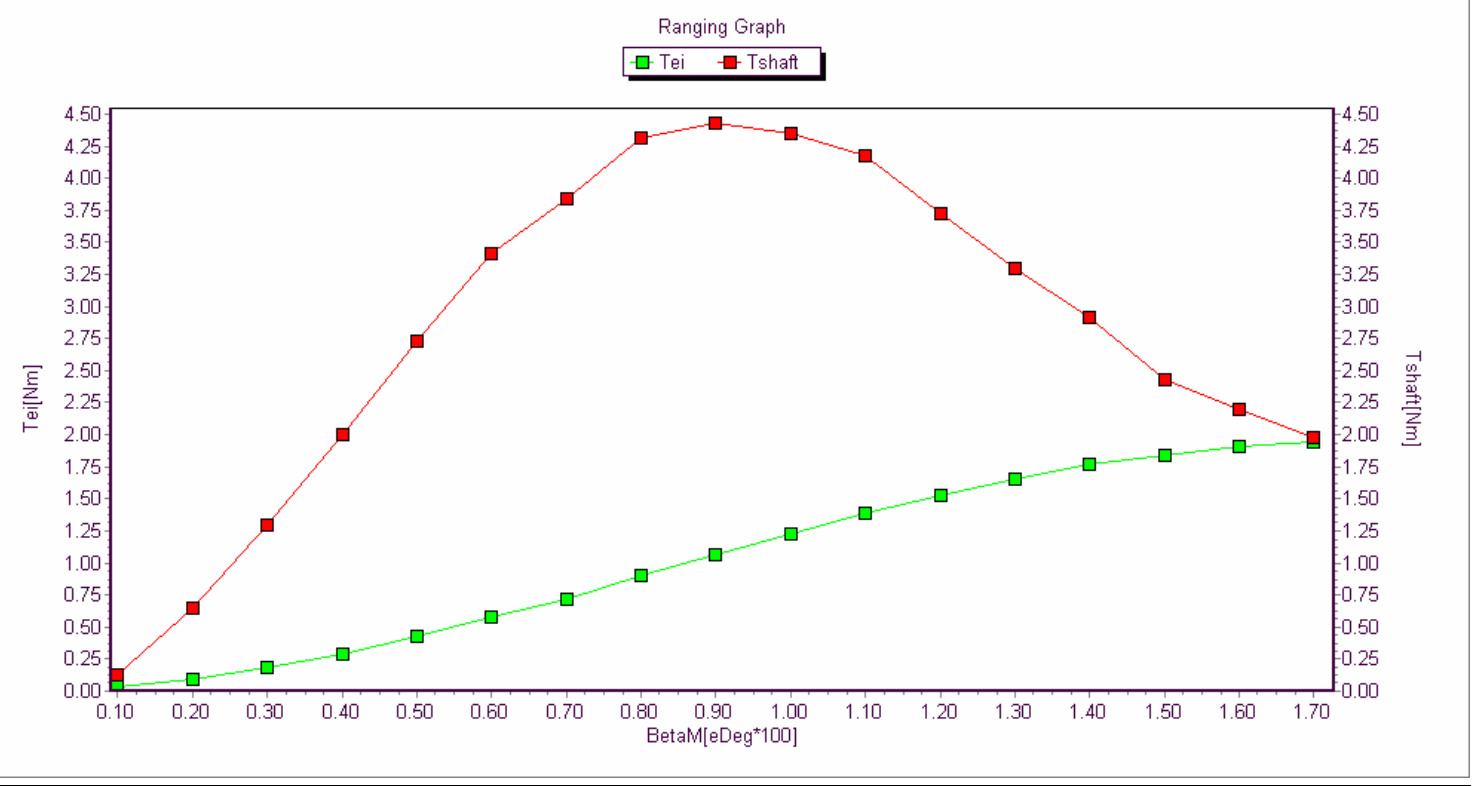

Fig. 1. Magnet torque and total shaft torque of a four-pole inset reluctance-assisted PM motor for a range of magnet fractions.

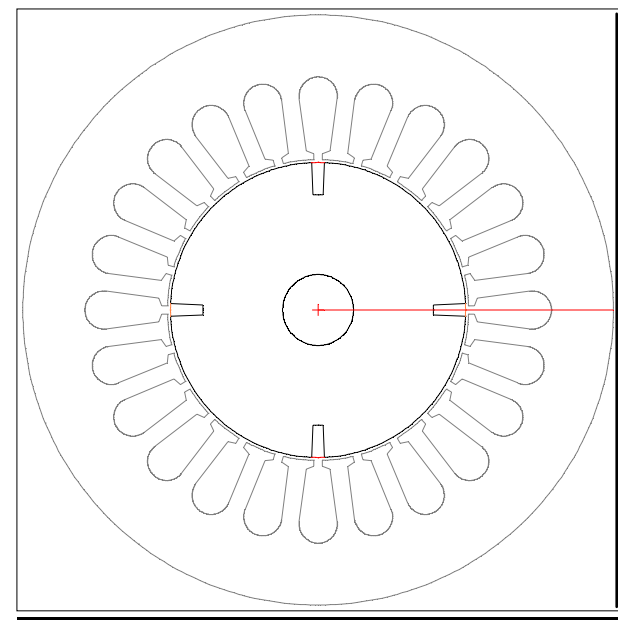

(a) Magnet fraction is almost zero.

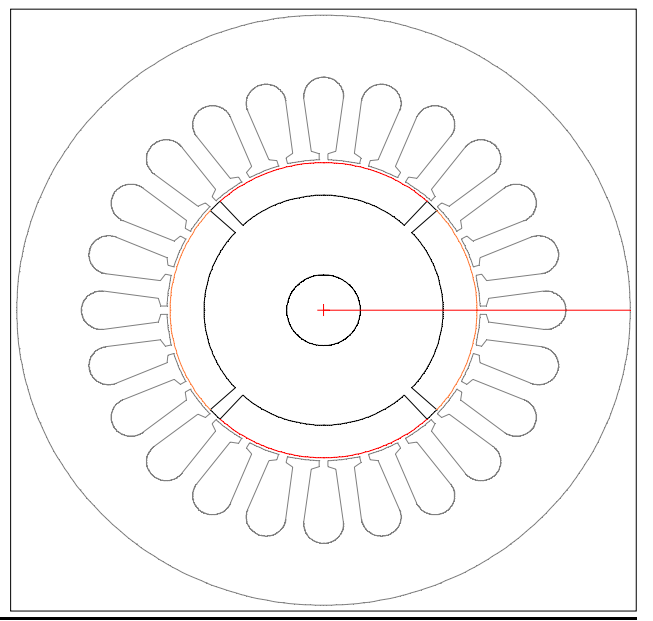

(b) Magnet fraction is almost one.

Fig. 2. Two possible configurations of an inset PM motor.

\subsection{DESIGN EQUATIONS OF A SYNCHRONOUS PM MOTOR WITH SALIENCY RATIO ABOVE ONE}

An elegant and useful approach to developing the steady-state design equations for a synchronous PM motor is to transform the stator variables, current and voltage, from a three-phase stationery-coordinate reference frame into a new, two-coordinate reference frame fixed in the rotor. The transformation is based on a two-axis theory after Blondel [4], Doherty and Nickle [5], and Park [6].

The currents and voltages in the most general form or a standard three-phase stationery-coordinate system are expressed as 


$$
\begin{array}{ll}
i_{a}=I_{a}^{p k} \cos \left(\omega t+\varepsilon_{a}\right) & v_{a}=V_{a}^{p k} \cos \left(\omega t+\delta_{a}\right) \\
i_{b}=I_{b}^{p k} \cos \left(\omega t+\varepsilon_{b}-2 \pi / 3\right) \\
i_{c}=I_{c}^{p k} \cos \left(\omega t+\varepsilon_{c}+2 \pi / 3\right)
\end{array} \quad \begin{array}{ll}
v_{b}=V_{b}^{p k} \cos \left(\omega t+\delta_{b}-2 \pi / 3\right) \\
v_{c}=V_{c}^{p k} \cos \left(\omega t+\delta_{c}+2 \pi / 3\right)
\end{array}
$$

where

$I_{a}^{p k}, I_{b}^{p k}, I_{c}^{p k}$ are the peak values for the time-domain current waveform, $V_{a}^{p k}=V_{b}^{p k}=V_{c}^{p k}=V^{p k}$ are the peak values for the time-domain voltage waveform, and $\varepsilon_{\mathrm{a},}, \varepsilon_{\mathrm{b}}, \varepsilon_{\mathrm{c}}$ and $\delta_{\mathrm{a}}, \delta_{\mathrm{b}}, \delta_{\mathrm{c}}$ are the angles by which the current and voltages, respectively, are shifted with respect to the time reference.

The instantaneous values of $\mathrm{i}_{\mathrm{a}}, \mathrm{i}_{\mathrm{b}}, \mathrm{i}_{\mathrm{c}}, \mathrm{v}_{\mathrm{a}}, \mathrm{v}_{\mathrm{b}}$, and $\mathrm{v}_{\mathrm{c}}$ can be viewed as the projections of two sets of vectors, $I_{a, b, c}^{p k}$ and $\mathrm{V}_{a, b, c}^{p k}$ rotating at the angular speed, $\omega \mathrm{t}$, with time shifts of $\varepsilon_{\mathrm{a}, \mathrm{b}, \mathrm{c}} / \omega$ and $\delta_{\mathrm{a}, \mathrm{b}, \mathrm{c}} / \omega$ respectively, on the axis of abscissas of a stationary frame of reference.

By changing the frame of reference to one rotating synchronously at angular speed $\omega$, the projection of the $I_{a, b, c}^{p k}$ and $\mathrm{V}_{a, b, c}^{p k}$ vectors over the rotating $\mathrm{x}$ - and y-axes will remain constant in time. Their value will depend on the angle between the rotating axis and the time reference.

This is shown mathematically as in the following equations. Let us compute the sum of the projections of the instantaneous values of the three phases over the $\mathrm{x}$ - and $\mathrm{y}$-axes of some arbitrary-rotating frame

$$
I_{x}=i_{a} \cos (\theta)+i_{b} \cos \left(\theta-\frac{2 \pi}{3}\right)+i_{c} \cos \left(\theta+\frac{2 \pi}{3}\right)
$$

and

$$
I_{y}=i_{a} \cos \left(\theta+\frac{\pi}{2}\right)+i_{b} \cos \left(\theta-\frac{2 \pi}{3}+\frac{\pi}{2}\right)+i_{c} \cos \left(\theta+\frac{2 \pi}{3}+\frac{\pi}{2}\right),
$$

which is

$$
I_{y}=-i_{a} \sin (\theta)-i_{b} \sin \left(\theta-\frac{2 \pi}{3}\right)-i_{c} \sin \left(\theta+\frac{2 \pi}{3}\right),
$$

where $\theta$ represents the angle between the new rotating $\mathrm{x}$-axis and the zero-time reference of the instantaneous waveforms.

In a balanced system $I_{a}^{p k}=I_{b}^{p k}=I_{c}^{p k}=I^{p k}, \varepsilon_{\mathrm{a}}=\varepsilon_{\mathrm{b}}=\varepsilon_{\mathrm{c}}=\varepsilon, \delta_{\mathrm{a}}=\delta_{\mathrm{b}}=\delta_{\mathrm{c}}=\delta$, and $V_{a}^{p k}=V_{b}^{p k}=V_{c}^{p k}=V^{p k}$. Then substituting (1) into (2) and (3) and employing the trigonometric identities we have

$$
\cos (M) \cos (N)=\frac{1}{2}[\cos (M+N)+\cos (M-N)]
$$

and 


$$
\cos (M) \sin (N)=\frac{1}{2}[\sin (M+N)-\sin (M-N)]
$$

one obtains

$$
I_{x}=\frac{3}{2} \mathrm{I}^{\mathrm{pk}} \cos (\omega t-\theta+\varepsilon)
$$

and

$$
I_{y}=+\frac{3}{2} I^{p k} \sin (\omega t-\theta+\varepsilon)
$$

Equations (4) and (5) lead to a time-independent current in the rotating x-y rotor frame which is

$$
I_{\text {rotor }}=\sqrt{I_{x}+I_{y}}=\frac{3}{2} I^{p k}
$$

In addition, if the angle $\theta$ is chosen as $\theta=\omega \mathrm{t}$, then the rotating frame is synchronized and the current projections from Eq. (4) become the time-independent equations

$$
I_{x}=\frac{3}{2} I^{p k} \cos (\varepsilon)
$$

and

$$
I_{y}=\frac{3}{2} I^{p k} \sin (\varepsilon) .
$$

It is customary to refer to the $\mathrm{x}$ - and $\mathrm{y}$-axes of the synchronously-rotating frame as the $\mathrm{d}$ - and q-axes respectively.

The equations show that the value of $\varepsilon$, which is controlled by the inverter, determines how much of the total current, $\mathrm{I}_{\text {rotor, }}$, is projected along the q-axis which produces torque interacting with the PM, or along the d-axis, which produces torque when there is saliency in the rotor and can be used to weaken the magnetic field in the air-gap to allow higher speed operation.

In order to make the current, $I_{\text {rotor }}$, in the rotating frame equal in value to the current, $I^{p k}$, in the stationary reference frame, Blondel introduced a factor $2 / 3$ in front of the transformation (2) and (3) leading to the transformation named after him, which is 


$$
B=\frac{2}{3}\left|\begin{array}{ccc}
\cos (\theta) & \cos \left(\theta-\frac{2 \pi}{3}\right) & \cos \left(\theta+\frac{2 \pi}{3}\right) \\
-\sin (\theta) & -\sin \left(\theta-\frac{2 \pi}{3}\right) & -\sin \left(\theta+\frac{2 \pi}{3}\right) \\
\frac{1}{2} & \frac{1}{2} & \frac{1}{2}
\end{array}\right| .
$$

In matrix notation, the three-phase stationery currents and voltages may be expressed as

$$
i_{P}=\left|\begin{array}{c}
i_{a} \\
i_{b} \\
i_{c}
\end{array}\right| \text { and } v_{P}=\left|\begin{array}{c}
v_{a} \\
v_{b} \\
v_{c}
\end{array}\right| .
$$

In the axis fixed in the rotor, the currents resulting from the transformation are $I_{d}, I_{q}$, and $I_{0}$ where $I_{0}=\left(i_{a}+i_{b}+i_{c}\right) / 3$, is zero during balanced conditions. Likewise, the voltages resulting from the transformation are $V_{d}, V_{q}$, and $V_{o}$ where $V_{o}=\left(v_{a}+v_{\mathrm{b}}+v_{c}\right) / 3$, is also zero during balanced conditions. Blondel's currents and voltages expressed in matrix notation are

$$
I_{B}=\left|\begin{array}{c}
I_{d} \\
I_{q} \\
I_{o}
\end{array}\right| \text { and } V_{B}=\left|\begin{array}{c}
V_{d} \\
V_{q} \\
V_{o}
\end{array}\right| \text {. }
$$

The inverse of Blondel's transformation matrix is

$$
\mathrm{B}^{-1}=\left|\begin{array}{ccc}
\cos (\theta) & -\sin (\theta) & 1 \\
\cos \left(\theta-\frac{2 \pi}{3}\right) & -\sin \left(\theta-\frac{2 \pi}{3}\right) & 1 \\
\cos \left(\theta+\frac{2 \pi}{3}\right) & -\sin \left(\theta+\frac{2 \pi}{3}\right) & 1
\end{array}\right| .
$$

The transformations relate the phase and Blondel currents and voltages as

$$
I_{B}=B i_{P}, i_{P}=[B]^{-1} I_{B} ;
$$

and

$$
V_{B}=B v_{P}, v_{P}=[B]^{-1} V_{B} .
$$

Physically this transformation makes the magneto-motive force ( $\mathrm{mmf}$ ) wave, which is induced by the currents in the stationery system and rotates at the synchronous speed determined by the three-phase signals, appear to be fixed in the rotor-coordinate system. This facilitates physical conceptualization. 
Using current in Eq. (13) and the rule that the transpose of the product of two matrices is the product of the transposes in reverse order, $I_{B}^{T}=i_{p}^{T} B^{T}$ we find that the transformed square of the Blondel current for a balanced system is

$$
I_{\text {Blondel }}^{2}=I_{d}^{2}+I_{q}^{2}=I_{B}^{T} I_{B}=i_{P}^{T} B^{T} B i_{P}=I^{p k^{2}}
$$

This verifies that the Blondel current equals the peak current in the stationery system. The same is true for the voltage. This transformation conveniently connects currents and voltages in the two systems.

The power of the stationery system must be invariant under transformation. Using a matrix operation similar to that used to obtain Eq. (14) it follows that

$$
\begin{aligned}
P^{i n}= & v_{a} i_{a}+v_{b} i_{b}+v_{c} i_{c}=v_{P}^{T} i_{P}=V_{B}^{T}\left[B^{-1}\right]^{T} B^{-1} I_{B}= \\
& \frac{3}{2}\left[V_{d} I_{d}+V_{q} I_{q}+2 V I_{0}\right]=\frac{3}{2}\left[V_{d} I_{d}+V_{q} I_{q}\right]
\end{aligned}
$$

where the 3 comes from the number of phases, 2 converts the peak values of voltage and current to rootmean square (rms) values, and the $I_{0}$ disappears because the current is balanced.

There are different transformations that have been used, such as the Park transformation which replaces the pre-factor, $2 / 3$, by $\sqrt{2 / 3}$ and replaces the $1 / 2$ elements by $\sqrt{1 / 2}$.

Park's transformation and inverse transformation are

$$
\mathrm{P}=\sqrt{\frac{2}{3}}\left|\begin{array}{ccc}
\cos (\theta) & \cos \left(\theta-\frac{2 \pi}{3}\right) & \cos \left(\theta+\frac{2 \pi}{3}\right) \\
-\sin (\theta) & -\sin \left(\theta-\frac{2 \pi}{3}\right) & -\sin \left(\theta+\frac{2 \pi}{3}\right) \\
\sqrt{\frac{1}{2}} & \sqrt{\frac{1}{2}} & \sqrt{\frac{1}{2}}
\end{array}\right|,
$$

and

$$
\mathrm{P}^{-1}=\sqrt{\frac{2}{3}}\left|\begin{array}{ccr}
\cos (\theta) & -\sin (\theta) & \sqrt{\frac{1}{2}} \\
\cos \left(\theta-\frac{2 \pi}{3}\right) & -\sin \left(\theta-\frac{2 \pi}{3}\right) & \sqrt{\frac{1}{2}} \\
\cos \left(\theta+\frac{2 \pi}{3}\right) & -\sin \left(\theta+\frac{2 \pi}{3}\right) & \sqrt{\frac{1}{2}}
\end{array}\right| .
$$

One can see that the two differences between the $\mathrm{B}$ and $\mathrm{P}$ transformations are the $\mathrm{K}$ pre-factor and the number used to define the imbalance current, $i_{0}$. This pre-factor, $K$, determines the relation between the transformed currents and voltages and the corresponding three-phase currents and voltages. When $K=2 / 3$, the transformed current and voltage are the peak current and peak voltage in the stationary 
system. When $\mathrm{K}=\sqrt{2 / 3}$, the powers are the same and the transformed voltage can be viewed as the lineto-line voltage in the stationary system.

\subsection{EQUIVALENT CIRCUITS FOR DYNAMIC OPERATION IN THE SYNCHRONOUSLY-ROTATING ROTOR FRAME}

For dynamic operation, the d-axis and q-axis have equivalent circuits that may be used to control the motor. These equivalent circuits are shown in Fig. 3 and lead to the dynamic equations for a synchronous motor with saliency which are

$$
L_{q} \frac{d I_{q}}{d t}=\left(V_{q}-R I_{q}-\omega_{e} L_{d} I_{d}-E_{f}\right)
$$

and

$$
L_{d} \frac{d I_{d}}{d t}=\left(V_{d}-R I_{d}+\omega_{e} L_{q} I_{q}\right)
$$

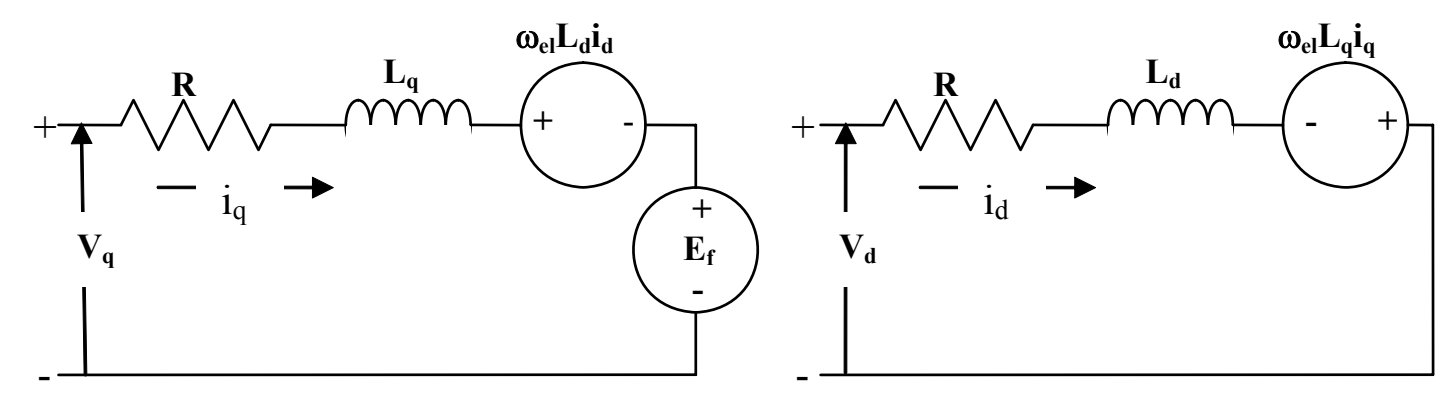

(a) Equivalent q-axis circuit.

(b) Equivalent d-axis circuit.

Fig. 3. Equivalent d-q circuits of a synchronous motor in the synchronously-rotating reference frame.

For steady-state operation, $\frac{\mathrm{dI}_{\mathrm{q}}}{\mathrm{dt}}=\frac{\mathrm{dI}_{\mathrm{d}}}{\mathrm{dt}}=0$; thus the terms in parentheses in Eqs. (18) and (19) are equal to zero. Multiplying the parenthesized zero term in Eq. (18) by $I_{q}$ and the parenthesized zero term in Eq. (19) by $I_{d}$ and simplifying, we obtain the q-axis and d-axis expressions for power

$$
P_{q}^{i n}=V_{q} I_{q}=R I_{q}^{2}+\omega_{e} L_{d} I_{d} I_{q}+I_{q} E_{f},
$$

and

$$
P_{d}^{i n}=V_{d} I_{d}=R I_{d}^{2}-\omega_{e} L_{q} I_{d} I_{q}
$$

From Eq. (15), which relates the power in the d-q system to the power in the balanced-stationary system, the amount of power converted from electric to magnetic form is now given by 


$$
P_{\text {converted }}=\frac{3}{2}\left[P_{q}^{i n}+P_{d}^{i n}-R\left(I_{q}^{2}+I_{d}^{2}\right)\right]=\frac{3}{2}\left[\omega_{e}\left(L_{d}-L_{q}\right) I_{d} I_{q}+I_{q} E_{f}\right]
$$

which leads to the torque equation for one pole pair,

$$
T=\frac{P_{\text {converted }}}{\omega_{m}}=\frac{3}{2}\left[\left(L_{d}-L_{q}\right) I_{d} I_{q}+\frac{I_{q} E_{f}}{\omega_{e}}\right] .
$$

Since $L_{q} \geq L_{d}$, positive values of $I_{d}$ reduce the power and torque; consequently, $I_{d}$ must be negative to obtain increased torque. The parenthesized zero terms in Eqs. (18) and (19) yield expressions in Eqs. (24) and (25) for $V_{q}$ and $V_{d}$,

$$
V_{q}=R I_{q}+\omega_{e} L_{d} I_{d}+\omega_{e} \lambda_{m}
$$

and

$$
V_{d}=R I_{d}-\omega_{e} L_{q} I_{q}
$$

With the relation between the back-electromotive force (back-emf) and the flux linkages of the magnet, $E_{f}=\omega_{e} \lambda_{m}$, and the definition, $P_{\text {converted }}=\frac{3}{2}\left[P_{q}^{i n}-I_{q}^{2} R+P_{d}^{i n}-I_{d}^{2} R\right]$, Eqs. (20) and (21) become

$$
P_{\text {converted }}=\frac{3}{2} \omega_{e} I_{q}\left[\lambda_{m}-I_{d}\left(L_{q}-L_{d}\right)\right]
$$

For a balanced system, the current in the stationary three-phase system is related to the total current in the d-q system by Eq. (14).

The d- and q-circuits are $90^{\circ}$ apart forming an orthogonal system as shown in Fig. 4, which uses the convention that $I_{d}$ along the positive $d$-axis is positive so that a negative value for $I_{d}$ is necessary to increase the power. 


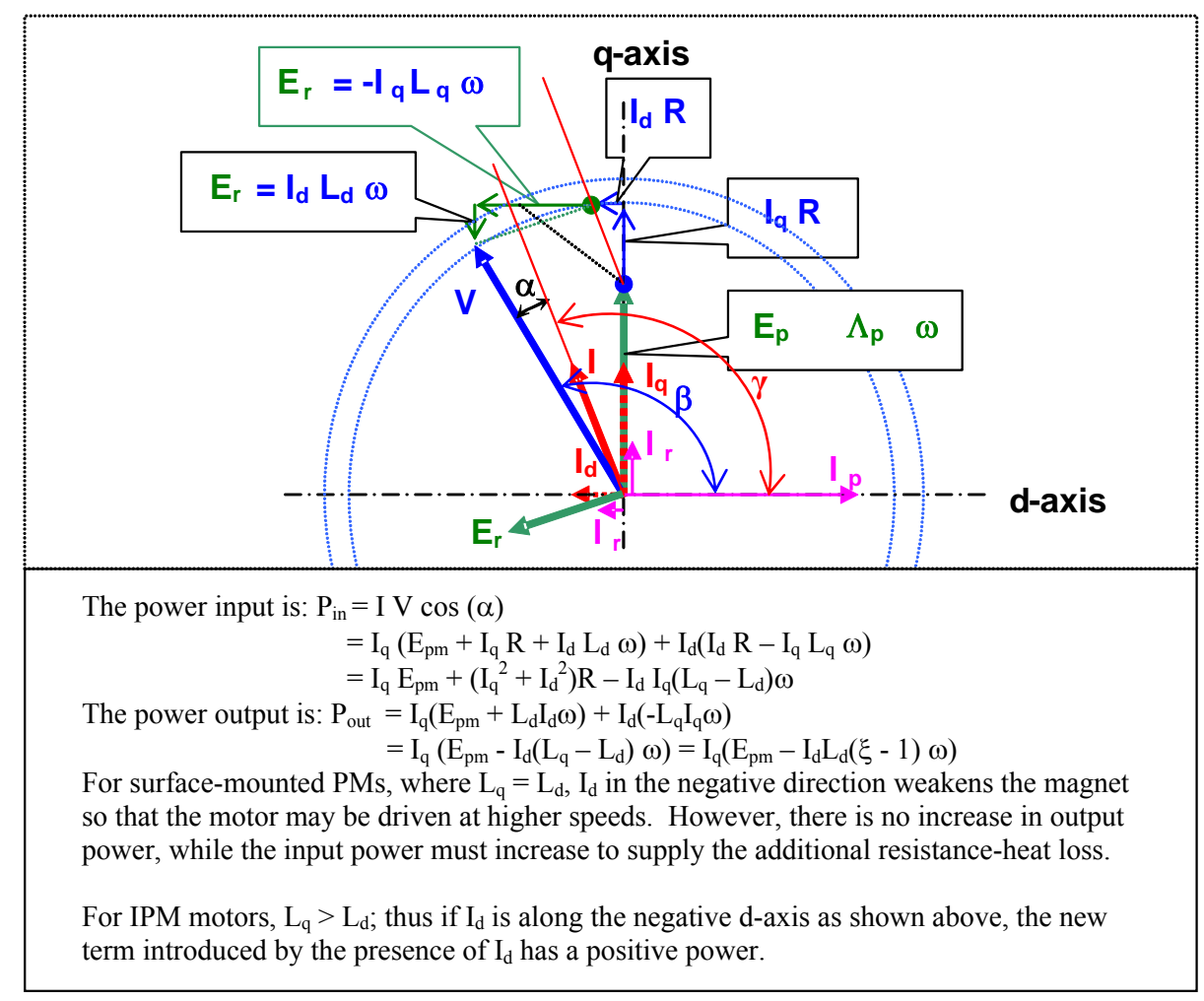

Fig. 4. Phasor diagram of the $d$ - and q-axes of a PM motor employing flux weakening ( $I_{d}$ in the second quadrant).

Since $X_{q}=\omega L_{q}$ and $X_{d}=\omega L_{d}$, the above equation for output power is

$$
P_{\text {out }}=I_{q} E_{p m}-I_{q} I_{d}\left(X_{q}-X_{d}\right)
$$

From the phasor diagram in Fig. $3, \mathrm{~V}_{\mathrm{q}}=\mathrm{E}_{\mathrm{pm}}+\mathrm{X}_{\mathrm{d}} \mathrm{I}_{\mathrm{d}}+\mathrm{I}_{\mathrm{q}} \mathrm{R}$ and $V_{d}=-X_{q} I_{q}+I_{d} R$. When solved for $I_{q}$ and $I_{d}$, one obtains the relations $I_{q}=-\frac{V_{d}}{X_{q}}$ and $I_{d}=\frac{V_{q}-E_{p m}}{X_{d}}$. Substituting the expressions for $I_{q}$ and $I_{d}$ into Eq. (27) yields

$$
P_{\text {out }}=-\frac{V_{d} E_{p m}}{X_{q}}+\frac{V_{d}}{X_{q}} \frac{\left(V_{q}-E_{p m}\right)}{X_{d}}\left(X_{q}-X_{d}\right) \text {, }
$$

which becomes

$$
\mathrm{P}_{\text {out }}=-\frac{\mathrm{V}_{\mathrm{d}} \mathrm{E}_{\mathrm{pm}}}{\mathrm{X}_{\mathrm{q}}}+\mathrm{V}_{\mathrm{d}} \mathrm{V}_{\mathrm{q}}\left(\frac{1}{\mathrm{X}_{\mathrm{d}}}-\frac{1}{\mathrm{X}_{\mathrm{q}}}\right)-\mathrm{V}_{\mathrm{d}} \mathrm{E}_{\mathrm{pm}}\left(\frac{1}{\mathrm{X}_{\mathrm{d}}}-\frac{1}{\mathrm{X}_{\mathrm{q}}}\right)
$$

The first term, which one might think is the power generated by the PM, cancels the very last term giving 


$$
P_{\text {out }}=-\frac{V_{d} E_{p m}}{X_{d}}+V_{d} V_{q}\left(\frac{1}{X_{d}}-\frac{1}{X_{q}}\right) .
$$

Substituting $\mathrm{V}_{\mathrm{d}}=\mathrm{V} \cos \beta$ and $\mathrm{V}_{\mathrm{q}}=\mathrm{V} \sin \beta$ leads to

$$
\mathrm{P}_{\mathrm{out}}=-\frac{\mathrm{VE}_{\mathrm{pm}} \cos \beta}{\mathrm{X}_{\mathrm{d}}}+\frac{\mathrm{V}^{2}}{2} \sin (2 \beta)\left(\frac{1}{\mathrm{X}_{\mathrm{d}}}-\frac{1}{\mathrm{X}_{\mathrm{q}}}\right)
$$

When Pout is expressed in terms of current as in Eq. (27), one is tempted to choose the $I_{q} E_{p m}$ term on the right as the power generated by the PM, especially since the second term vanishes when $X_{q}=X_{d}$. Similarly, when $P_{\text {out }}$ is expressed in terms of voltage as in Eq. (31), one is tempted to choose the term containing $E_{p m}$ as the power generated by the PM, especially since, once again, the second term vanishes when $X_{q}=X_{d}$. Recall, however, that in the process of deriving Eq. (31), a term in the reluctance containing $E_{p m}$ canceled the very term we considered a candidate for power generated by the PM in Eq. (27).

Using the equalities, $\mathrm{I}_{\mathrm{q}}=\mathrm{I} \sin \gamma$ and $\mathrm{I}_{\mathrm{d}}=\mathrm{I} \cos \gamma$, Eq. (27) may be written as

$$
\mathrm{P}_{\mathrm{out}}=\mathrm{IE}_{\mathrm{pm}} \sin \gamma-\mathrm{I}^{2} \sin \gamma \cos \gamma\left(\mathrm{X}_{\mathrm{q}}-\mathrm{X}_{\mathrm{d}}\right)=\mathrm{IE}_{\mathrm{pm}} \sin \gamma-\frac{\mathrm{I}^{2}}{2} \sin (2 \gamma)\left(\mathrm{X}_{\mathrm{q}}-\mathrm{X}_{\mathrm{d}}\right)
$$

We now examine the power expressions with voltage- and current-phase angles referenced to the q-axis, which is along the back-emf instead of the d-axis. When the voltage phase angle, $\delta$, is referenced to the back-emf so that $\delta=\beta-\frac{\pi}{2}$, the trigonometric identities are $\cos \beta=-\sin \delta$ and $\sin (2 \beta)=-\sin (2 \delta)$. When applied to Eq. (31), the power expression becomes

$$
\mathrm{P}_{\mathrm{out}}=\frac{\mathrm{VE}_{\mathrm{pm}} \sin \delta}{\mathrm{X}_{\mathrm{d}}}-\frac{\mathrm{V}^{2}}{2} \frac{\left(\mathrm{X}_{\mathrm{q}}-\mathrm{X}_{\mathrm{d}}\right)}{\mathrm{X}_{\mathrm{q}} \mathrm{X}_{\mathrm{d}}} \sin (2 \delta) \text {. }
$$

Likewise, when the current-phase angle, $\varepsilon$, is referenced to the q-axis instead of the d-axis we see that $\varepsilon=\gamma-\pi / 2$ whose trigonometric identities are $\sin \gamma=\cos \varepsilon$ and $\sin 2 \gamma=-\sin 2 \varepsilon$. Substituting into Eq. (32) gives

$$
\mathrm{P}_{\mathrm{out}}=\mathrm{IE}_{\mathrm{pm}} \cos \varepsilon+\frac{\mathrm{I}^{2}}{2} \sin (2 \varepsilon)\left(\mathrm{X}_{\mathrm{q}}-\mathrm{X}_{\mathrm{d}}\right)
$$

In this expression, the useful power is the product of the current, back-emf, and the cosine of the angle between them, as it should be.

The following table shows the PM torque and reluctance torque expressed as a function of current and voltage with $\xi=\mathrm{X}_{\mathrm{q}} / \mathrm{X}_{\mathrm{d}}=\mathrm{L}_{\mathrm{q}} / \mathrm{L}_{\mathrm{d}} \geq 1$ being the saliency ratio. 
Table. 1. PM and reluctance torque equations expressed as I and V functions

\begin{tabular}{|l|c|c|c|}
\hline & PM Torque & Reluctance Torque & $\begin{array}{c}\text { Phase referenced to } \\
\text { back-emf (q-axis) }\end{array}$ \\
\hline Current Expression & $\mathrm{I} \frac{\mathrm{E}_{\mathrm{pm}}}{\omega} \cos \varepsilon$ & $\frac{\mathrm{I}^{2}}{2} \frac{\mathrm{X}_{\mathrm{d}}}{\omega}(\xi-1) \sin (2 \varepsilon)$ & $\varepsilon$ \\
\hline Voltage Expression & $\frac{\mathrm{V}}{\mathrm{X}_{\mathrm{d}}} \frac{\mathrm{E}_{\mathrm{pm}}}{\omega} \sin \delta$ & $-\frac{\mathrm{V}^{2}}{2} \frac{1}{\mathrm{X}_{\mathrm{q}}} \frac{(\xi-1)}{\omega} \sin (2 \delta)$ & $\delta$ \\
\hline
\end{tabular}




\section{MODELING APPROACH}

The most practical approach to modeling the performance of a PM motor with saliency is based on lumped-parameters and the $\mathrm{d}-\mathrm{q}$ transformation. As shown in the previous chapter, these governing equations are

$$
\begin{aligned}
& V_{q}=R I_{q}+\omega_{e} L_{d} I_{d}+\omega_{e} \lambda_{m}, \\
& V_{d}=R I_{d}-\omega_{e} L_{q} I_{q},
\end{aligned}
$$

and

$$
P_{\text {converted }}=\frac{3}{2} \omega_{e} I_{q}\left[\lambda_{m}-I_{d}\left(L_{q}-L_{d}\right)\right]
$$

These lumped-parameter equations facilitate understanding of the phenomena involved but require the determination of lumped inductances, resistance, and flux linkages with the degree of detail appropriate for the simulation goals. Most challenging is the characterization of magnetic saturation since, especially in the case of IPM motors, the magnetic-flux paths vary significantly with the rotor's position relative to the stator generated rotating field and also with the magnitude of the stators currents. It is best to have measured values of the lumped parameters. Next best is to obtain them by means of finite-element computations. However, most often lumped parameters are obtained by means of calculations based on geometry, equivalent circuits, and adjustment factors.

To complete the set of equations needed, we state the fundamental relationships for terminal voltage and phase current with their respective phase angles whose zero reference is the d-axis, as seen in Fig. 4,

$$
\begin{aligned}
& V_{t}=\sqrt{V_{d}^{2}+V_{q}^{2}}, \quad \tan (\beta)=\frac{V_{q}}{V_{d}}, \\
& I_{t}=\sqrt{I_{d}^{2}+I_{q}^{2}}, \quad \tan (\gamma)=\frac{I_{q}}{I_{d}} .
\end{aligned}
$$

The angle between the current and the voltage is then $\alpha=\beta-\gamma$; consequently, the power factor is $p f=\cos (\alpha)$ and the power input is

$$
P_{\text {input }}=\frac{3}{2} V_{t} I_{t} \cos (\alpha)=\frac{3}{2}\left(V_{d} I_{d}+V_{q} I_{q}\right)
$$

Since $P_{\text {converted }}=P_{\text {input }}-P_{\text {ohmic_loss }}$, the efficiency is

$$
\text { Efficiency }=\frac{P_{\text {converted }}-P_{\text {mag_loss }}}{P_{\text {input }}}=1-\frac{P_{\text {ohmic_loss }}+P_{\text {mag_loss }}}{P_{\text {input }}} .
$$

We have pursued two simulation approaches to model these fundamental equations. One approach is analytical, implemented symbolically in Mathematica, and the other is purely numerical, implemented in 
LabVIEW. With Mathematica, the symbolic representations of the equations are manipulated algebraically using the rules of calculus to initially obtain sets of formulas for the performance parameters of interest and finally to find the control parameters that optimize performance. This is done by equating partial derivatives to zero, solving symbolically for the parameter of interest and solving the resulting equations with that parameter substituted.

In this chapter, we present the derivations of some of the equations of interest and apply them to an IPM motor referred to as Motor X. In the next chapter, we present the results of the numerical LabVIEW analysis.

\subsection{TERMINAL VOLTAGE UNDER CURRENT-PHASE ANGLE CONTROL}

An expression for the terminal voltage as a function of the current, current-phase angle, and electrical frequency can be obtained from Eqs. (24), (25), (27), and (28) as

$$
V_{t}=I_{t} \sqrt{\begin{array}{c}
R^{2}+\omega_{e}{ }^{2} L d^{2}\left(1+\left(\xi^{2}-1\right) \sin (\gamma)^{2}\right)-(\xi-1) R \omega_{e} L d \sin (2 \gamma)+\cdots \\
\cdots \quad 2 \omega_{e} L_{m b}\left(\omega_{e} L d \cos (\gamma)+R \sin (\gamma)\right)+\omega_{e}{ }^{2} L_{m b}{ }^{2}
\end{array}}
$$

with

$$
L_{m b}=\frac{\lambda_{m}}{I_{t}} \text { and } \xi=\frac{L q}{L d}
$$

The current-limited region is below base speed. In this region, the applied voltage must be chopped to prevent the current from exceeding $I_{\max }$. The amplitude-modulation ratio is the ratio of the terminal voltage from Eq. (39) with $I_{t}=I_{\max }$ to the source voltage, i.e. $m=\frac{V_{t}\left[I_{\max }, \omega_{e}, \gamma\right]}{V_{\text {source }}} \leq 1$. The terminal voltage thus depends on the speed, $\Omega_{r p m}$, through its relation to electrical frequency, as well as the currentcontrol angle. That relation is $\omega_{e}=\Omega_{r p m} 2 \pi / 60 \mathrm{x}$ the number of pole pairs.

The voltage-limited region is above base speed. In this region, the back-emf prevents the current from reaching its maximum value even at full voltage. In the voltage-limited region, the motor's currentcarrying capacity is not fully used.

The optimal value of the current-control angle, $\gamma$, depends on the value of the performance measure selected for optimization. Typical performance measures are power output, torque, power factor, or efficiency.

\subsection{BASE SPEED}

The speed at which the magnitude of the terminal voltage equals the available voltage when the current is at its limit defines the motor's base speed. Thus, solving Eq. (39) for $\omega_{e}$, with $V_{t}=V_{\text {source }}$ and $I_{t}=I_{\max }$, yields the expression 
$\omega_{\text {ebase }}=\frac{\left(\begin{array}{l}-\frac{\mathrm{R}}{2}\left(2 \mathrm{~L}_{\mathrm{mb}} \sin (\gamma)-(\xi-1) \mathrm{Ld} \sin (2 \gamma)\right)+\ldots \\ \cdots \sqrt{\mathrm{R}^{2}\left(\mathrm{~L}_{\mathrm{mb}}-(\xi-1) \mathrm{Ld} \cos (\gamma)\right)^{2} \sin (\gamma)^{2}-\left(\mathrm{R}^{2}-\mathrm{R}_{\mathrm{b}}{ }^{2}\right)\left(\left(\mathrm{L}_{\mathrm{mb}}+\mathrm{Ld} \cos (\gamma)\right)^{2}+\xi^{2} \mathrm{Ld}^{2} \sin (\gamma)^{2}\right.}\end{array}\right)}{\mathrm{Ld}^{2}\left(1+\left(\xi^{2}-1\right) \sin (\gamma)^{2}\right)+2 \mathrm{Ld}_{\mathrm{mb}} \cos (\gamma)+\mathrm{L}_{\mathrm{mb}}{ }^{2}}$

where

$$
L_{m b}=\frac{\lambda_{m}}{I_{\max }} \text { and } R_{b}=\frac{V_{\text {source }}}{I_{\max }}
$$

As Eq. (40) shows, the base speed depends not only on the magnitudes of $\mathrm{V}_{\text {source }}$ and $\mathrm{I}_{\max }$, but also on the current-phase angle, $\gamma$, (Fig. 4) which may be controlled externally. Therefore, when a base speed is chosen it uniquely determines the current-phase angle, $\gamma_{0}$. Likewise, it also uniquely determines the voltage-phase angle, $\beta_{0}$.

\subsection{ATTAINABLE CURRENT UNDER CURRENT-PHASE ANGLE OR UNDER VOLTAGE-PHASE ANGLE CONTROL IN THE VOLTAGE-LIMITED REGION}

In the current-limited region below the base speed, the magnitude of the current is at most the design maximum, $I_{\max }$. The current's phase angle may vary with speed and will depend on the performance goal.

In the voltage-limited region above base speed, the maximum-terminal voltage is reached before the current reaches its maximum limit. In the voltage-limited region, the attainable current can be obtained from Eqs. (24), (25), (27), and (28). When the current-phase angle, $\gamma$, is being controlled, the current with $\mathrm{V}_{\mathrm{t}}=\mathrm{V}_{\text {source }}$ is

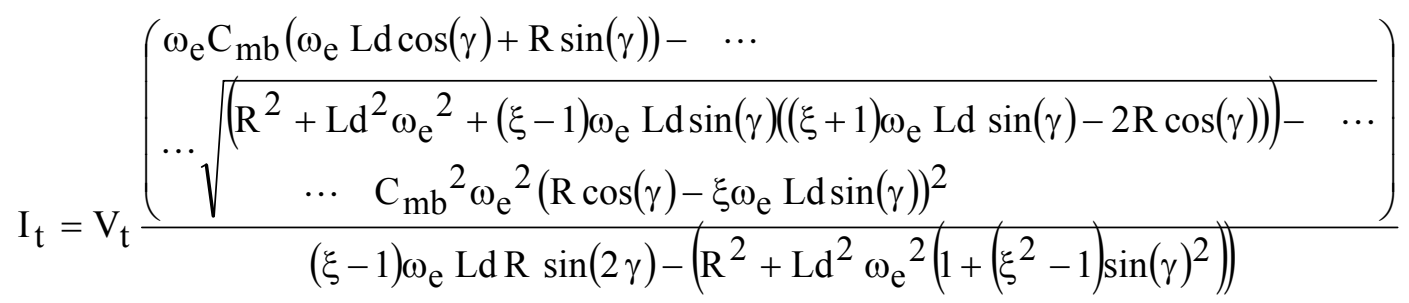

where

$$
\mathrm{C}_{\mathrm{mb}}=\frac{\lambda_{\mathrm{m}}}{\mathrm{V}_{\mathrm{t}}}
$$

When the voltage-phase angle $\beta$ is being controlled, the current with $\mathrm{V}_{\mathrm{t}}=\mathrm{V}_{\text {source }}$ is 


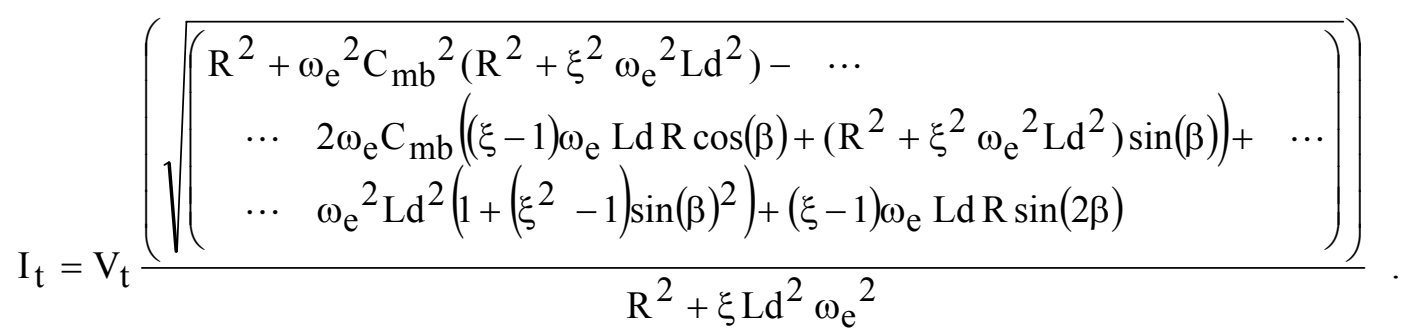

The magnitude of the current in this region depends on the control angle. A higher current does not necessarily produce more power since power depends on the phase angle; thus, as mentioned above, the control angle needs to be chosen to optimize the desired performance parameter.

\subsection{APPLICATION OF MOTOR X PARAMETERS TO VOLTAGE AND CURRENT EXPRESSIONS}

We now investigate the above expressions using a specific motor example defined by the parameters in Table 2 .

Table 2. Lumped parameters for Motor X

\begin{tabular}{|c|c|c|c|}
\hline $\begin{array}{l}\text { Phase inductance } \\
\text { through magnet, } L_{d}\end{array}$ & $0.952 \mathrm{mH}$ & $\begin{array}{c}\text { Number of turns } \\
\text { per coil }\end{array}$ & 9 \\
\hline $\begin{array}{l}\text { Phase-quadrature } \\
\text { inductance, } L_{q}\end{array}$ & $1.413 \mathrm{mH}$ & $\begin{array}{c}\text { Current-phase angle } \\
\text { wrt } \\
\text { d-axis, } \gamma_{0}{ }^{*} \\
\end{array}$ & $\begin{array}{l}2.65 \text { radians } \\
152^{\circ}\end{array}$ \\
\hline Flux linkages, $\lambda_{m}$ & $0.1208 \mathrm{~Wb}$ & $\begin{array}{c}\text { Voltage-phase angle } \\
\text { wrt } \\
\text { d-axis, } \beta_{\mathbf{0}}{ }^{*}\end{array}$ & $\begin{array}{l}3.49 \text { radians } \\
200^{\circ}\end{array}$ \\
\hline Phase resistance, $R$ & $0.049 \Omega$ & $\begin{array}{l}\text { Maximum rated } \\
\text { current, } \mathbf{I}_{t_{0}}\end{array}$ & $212.6 \mathrm{amps}$ \\
\hline Terminal voltage, $V_{t}$ & $245 \mathrm{~V}$ & Rated power, $P_{0}$ & $47.3 \mathrm{~kW}$ \\
\hline $\begin{array}{c}\text { Base speed, } \\
\text { electrical } \mathrm{rad} / \mathrm{s}, \omega_{\mathrm{e} 0} \\
\text { mechanical } \mathrm{rad} / \mathrm{s}, \omega_{\mathrm{m} 0} \\
\text { mechanical rpm, } \Omega\end{array}$ & $\begin{array}{r}1550 \\
387.5 \\
3770\end{array}$ & Number of pole pairs & 4 \\
\hline $\begin{array}{l}\text { Hysteresis loss factor, } \\
\mathrm{K}_{\mathrm{h}},\left(s^{2} / T^{1.93}\right)(W / l b)(l b)\end{array}$ & $\mathrm{K}_{\mathrm{h}}=5.8 \mathrm{e}^{-3} \frac{\mathrm{s}^{2}}{\mathrm{~T}^{1.93}} 2.2$ & $\begin{array}{l}\text { Eddy current loss } \\
\text { factor, } K_{\mathrm{e}}, \\
\left(s^{2} / T^{2}\right)(W / l b)(l b)\end{array}$ & $\mathrm{K}_{\mathrm{e}}=9.3 \mathrm{e}^{-6} \frac{\mathrm{s}^{2}}{\mathrm{~T}^{2}} 2.2$ \\
\hline
\end{tabular}

*Once a design-terminal voltage and current are established, selection of the electrical-base speed, which for Motor $\mathrm{X}$ is $1550 \mathrm{rad} / \mathrm{s}$, imposes unique values for $\gamma_{\mathrm{o}}$ and $\beta_{\mathrm{o}}$.

Figure 5 shows the base-speed dependence from Eq. (40) on the current-phase angle for Motor X. The maximum-base speed for Motor $\mathrm{X}$ values of $\mathrm{V}_{\text {source }}$ and $\mathrm{I}_{\max }$ occurs for $\gamma=180^{\circ}$ and is $3003 \mathrm{rad} / \mathrm{s}$; but this speed is not of interest because for $\gamma=180^{\circ}$ the power factor, which is the angle between back-emf and current and may be visualized using Fig. 4 , is $90^{\circ}$ so that the developed power is zero. 


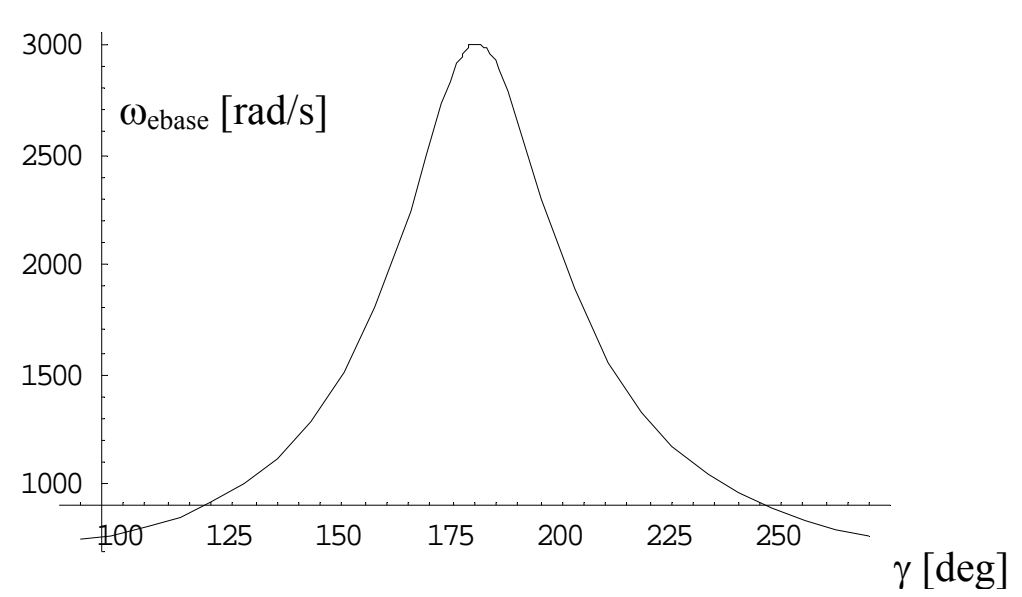

Fig. 5. Motor $\mathrm{X}$ base speed as a function of current-control angle.

(Maximum for $\gamma=180^{\circ}, \omega_{\text {ebase }} \max =\frac{\sqrt{\mathrm{Vt}^{2}-\mathrm{It}^{2} \mathrm{R}^{2}}}{\mathrm{Ld} \mathrm{It}-\lambda_{\mathrm{m}}}=\mathbf{3 0 0 3} \mathrm{rad} / \mathbf{s}$.)

Figure 6 shows the terminal-current dependence in the voltage-limited region on the current-phase angle, $\gamma$, and speed for Motor X from Eq. (41). The maximum current also corresponds to $\gamma=180^{\circ}$, which is useful to illustrate functional relationships between $\mathrm{I}_{\mathrm{t}}, \omega_{\mathrm{e}}$, and $\gamma$ but, once again, is of no physical interest because it produces no power. 


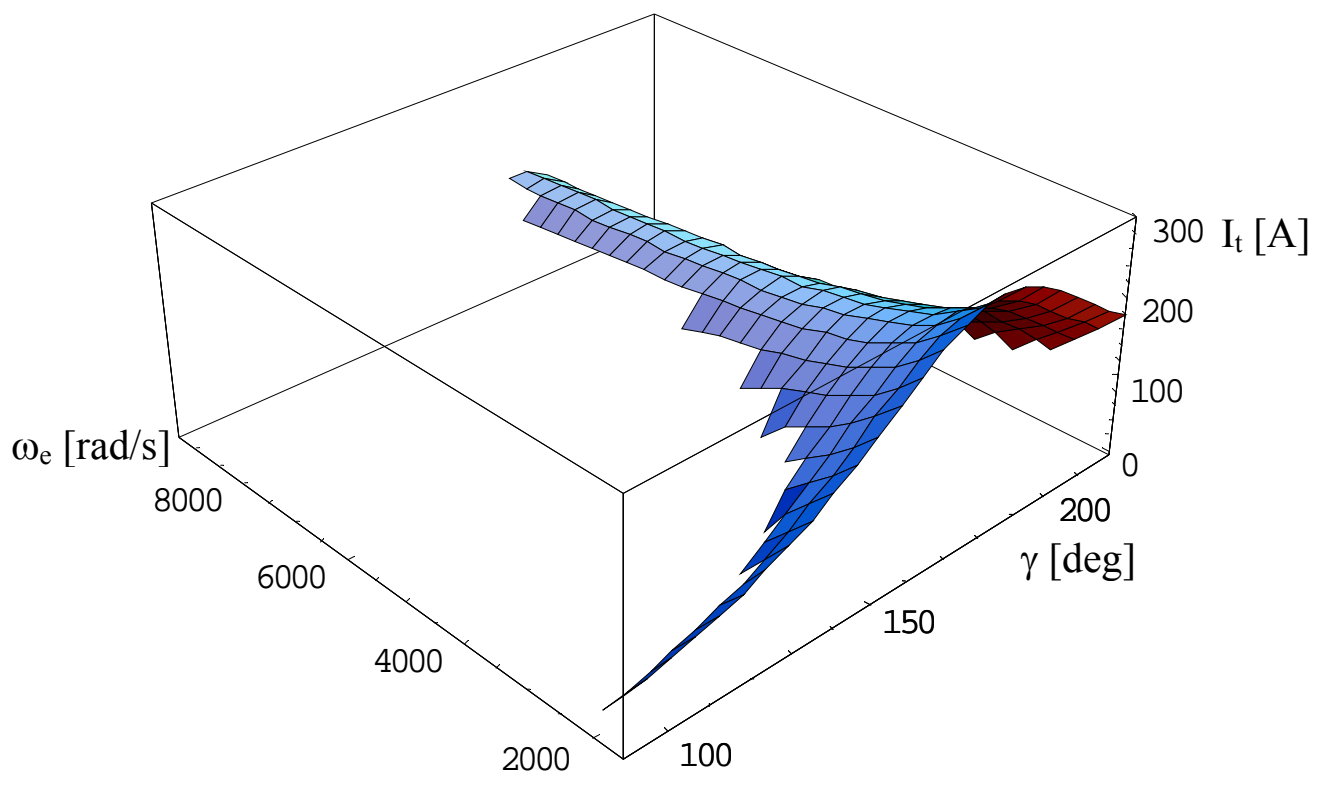

(a) As a function of speed and current-control angle.

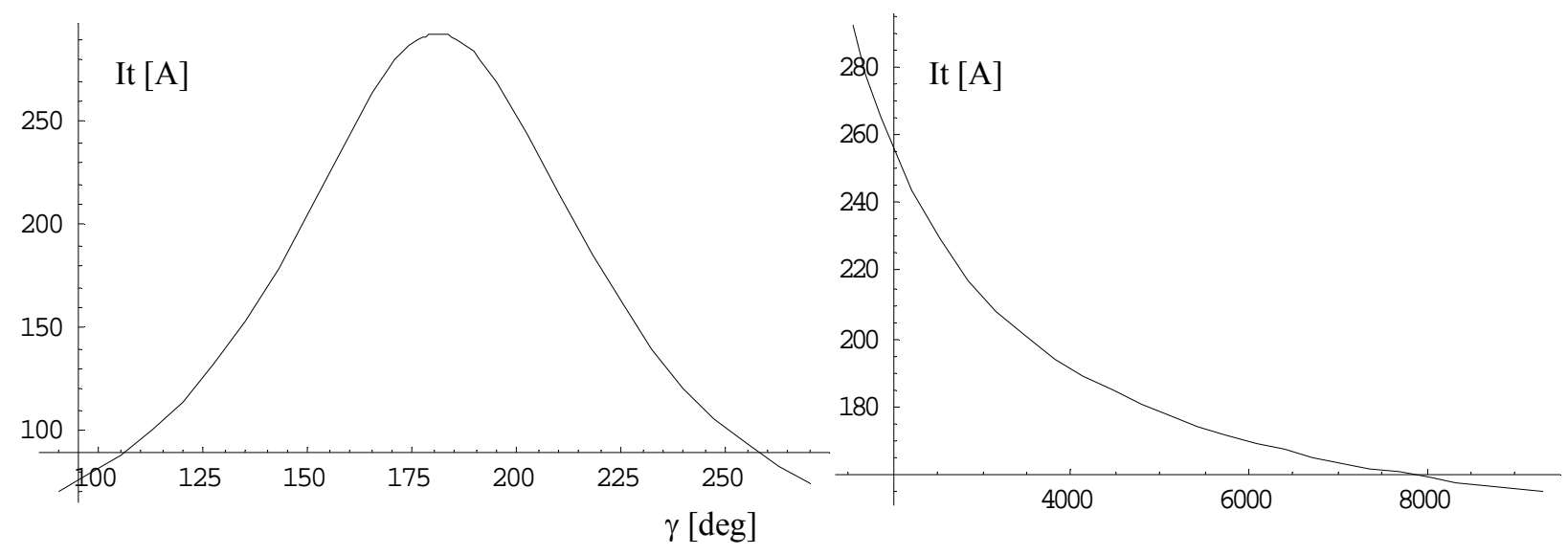

(b) As a function of current-control angle, $\gamma$, for base speed, $\omega_{\mathrm{e} 0}$.

(c) As a function of speed for $\gamma=180^{\circ}$.

Fig. 6. Motor $X$ with voltage-limited attainable current under $\gamma$ control.

Figure 7 shows the dependence of the maximum-attainable current in the voltage-limited region, on the voltage-phase angle, $\beta$, and speed for Motor $X$ from Eq. (42). Figures 7(a) and (b) show that the maximum-attainable current occurs at $\beta=270^{\circ}$, which again is useful to illustrate functional relationships, but is not of physical importance because it produces no power. Figure 7(c) shows the drop in current with speed for a fixed current angle of $200^{\circ}$, which is equal to the value of $\beta_{0}$ required by the base speed. When base speed is established first, which for Motor $X$ is $1550 \mathrm{rad} / \mathrm{s}$, unique values are imposed on $\gamma_{o}$ and $\beta_{o}$ as shown in Table 1 . 


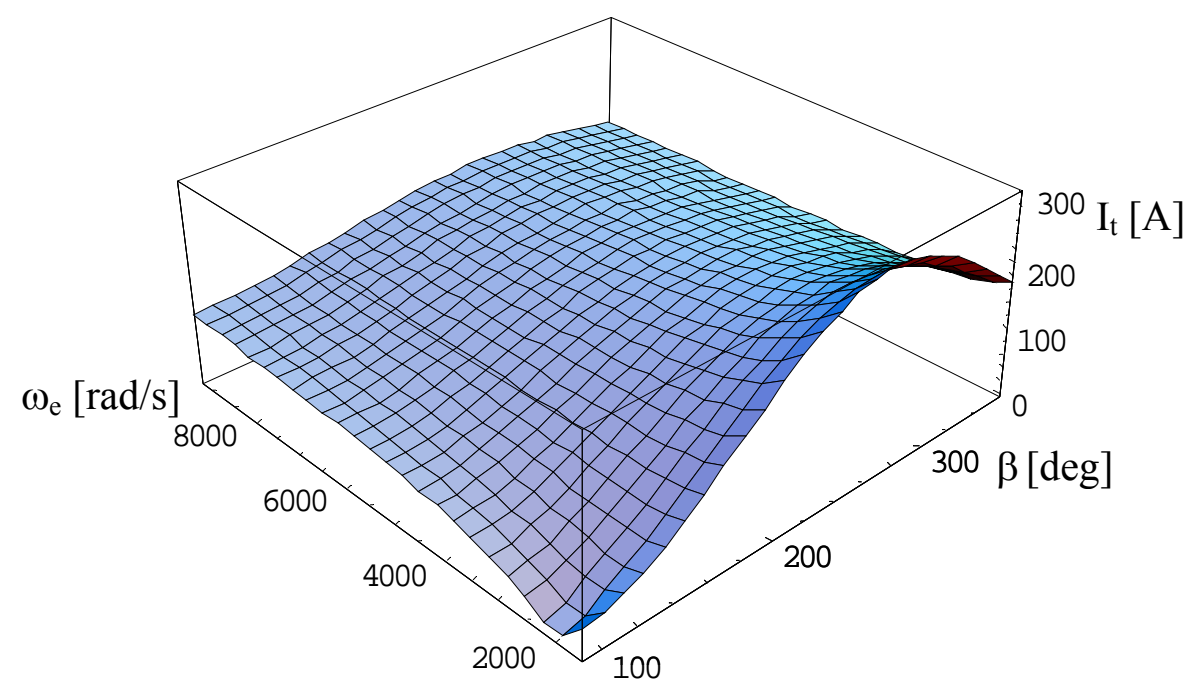

(a) As a function of speed and voltage-control angle.

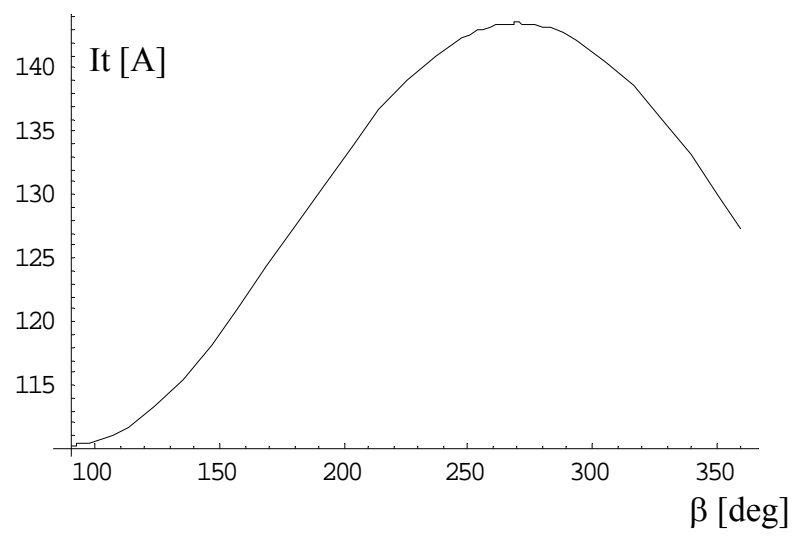

(b) Function of voltage-control angle for $\omega_{\mathrm{e} 0}$.

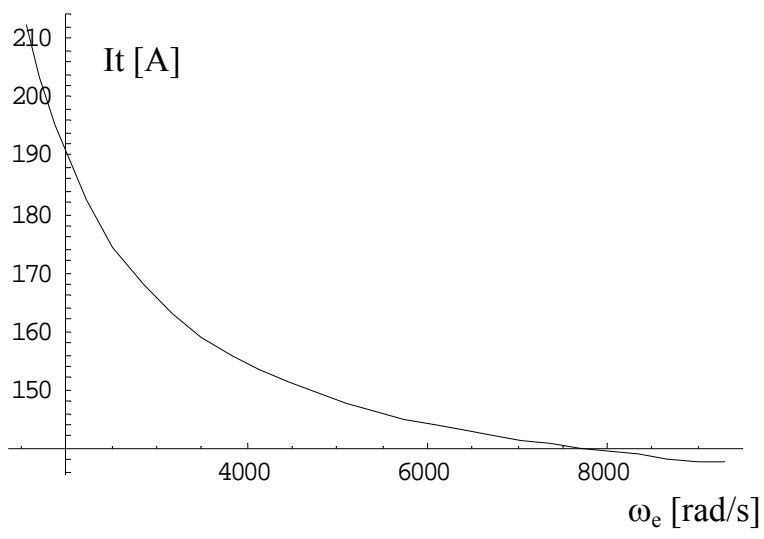

(c) Function of speed for $\beta=\beta_{0}=200^{\circ}$.

Fig. 7. Motor $X$ with voltage-limited current under $\beta$ control.

To determine the best control angle for each speed which corresponds to the optimal trajectories along the surfaces in Figs. 6(a) and 7(a), one must look at the performance parameter of interest which may be power, torque, and/or efficiency.

\subsection{POWER EXPRESSION USED FOR OPTIMIZATION}

The power output can be obtained by subtracting the ohmic and magnetic losses in the iron from the power input as shown in Eq. (29). Expressions for maximum power can be derived under control of either voltage-phase angle, $\beta$, or current-phase angle, $\gamma$. Derivation of maximum power controlled by the voltage-phase angle, known as $\beta$ control, leads to a less tractable expression and is discussed next for the voltage-limited region along with the nature of its intractability. The numerical solution is presented instead of a complicated multi-page expression. Section 2.6 derives a much simpler expression for maximum power controlled by the current-phase angle, known as $\gamma$ control, in the current-limited region.

From Eq. (26) one may obtain the functional form of $P_{\text {out }}\left(V_{t}, \beta\right)$ as 


$$
\begin{aligned}
\mathrm{P}_{\text {out }}\left(\mathrm{V}_{\mathrm{t}}, \beta\right)= & -\frac{3}{2} \frac{\mathrm{V}_{\mathrm{t}}^{2} \omega_{\mathrm{e}}\left(\omega_{\mathrm{e}}\left(\mathrm{RC}_{\mathrm{mb}}+\mathrm{Ld} \cos (\beta)\right)-\mathrm{R} \sin (\beta)\right)}{\left(\mathrm{R}^{2}+\mathrm{Ld}^{2} \omega_{\mathrm{e}}{ }^{2}\right)^{2}} \\
& \left(\begin{array}{c}
\mathrm{C}_{\mathrm{mb}}\left(\mathrm{R}^{2}+\xi^{2} \omega_{\mathrm{e}}{ }^{2} \mathrm{Ld}^{2}\right)+\cdots \\
\cdots(\xi-1) \mathrm{Ld}\left(\mathrm{R} \cos (\beta)+\xi \omega_{\mathrm{e}} \mathrm{Ld} \sin (\beta)\right)
\end{array}\right)-\mathrm{P}_{\mathrm{Fe}}
\end{aligned},
$$

where $C_{m b}=\frac{\lambda_{m}}{V_{t}}$ as in Eq. (42). The iron losses [7] are estimated to be

$$
P_{F e}=K_{e} \omega_{e}^{2} B_{\text {gap }}^{2}+K_{h} \omega_{e} B_{\text {gap }}^{1.93},
$$

where $K_{e}$ is the eddy-current-loss coefficient and $K_{h}$ is the hysteresis-loss coefficient. These are listed for Motor X in Table 1.

The negative sign in front of Eq. (43) indicates that the voltage-control angle, $\beta$, must be larger than a certain value to produce net power for motoring operation. This can be seen for the simplified case in which the iron and ohmic losses are neglected and $\mathrm{L}_{\mathrm{d}}=\mathrm{L}_{\mathrm{q}}$ so that $\xi=1$, which corresponds to no saliency. Then

$$
P_{\text {out }}\left[R=0, P_{F e}=0, \xi=1\right]=-\frac{3}{2} \frac{V_{t} \lambda_{m} \cos (\beta)}{L d}
$$

and when $\beta$ is between 90 and $270^{\circ}$, its cosine is negative and consequently $\mathrm{P}_{\text {out }}>0$.

The optimal-voltage angle, $\beta$, over the voltage-limited region above base speed may be obtained by making $\mathrm{V}_{\mathrm{t}}=\mathrm{V}_{\text {source }}$ in Eq. (43) and finding the value of $\beta$ for which $\partial \mathrm{P}_{\text {out }} / \partial \beta=0$. This equation is a fourth-degree polynomial in $\sin (\beta)$. The nature of its intractability is its four solutions in terms of $L_{d}, L_{q}$, $\mathrm{R}$, Vsource, $\omega_{\mathrm{e}}$, and $\lambda_{\mathrm{m}}$ which are too cumbersome to transcribe here. Instead, the numerical results are presented.

\subsection{NUMERICALLY DETERMINED MAXIMUM-POWER DELIVERY UNDER VOLTAGE CONTROL IN THE VOLTAGE-LIMITED REGION}

The power output according to Eq. (43), including iron losses, is shown in Fig. 8(a) and (b) as a function of speed for the full range of voltage-phase angles above base speed. Figure 8(b) superimposes the trajectory for maximum-power output on the surface in Fig. 8(a). 


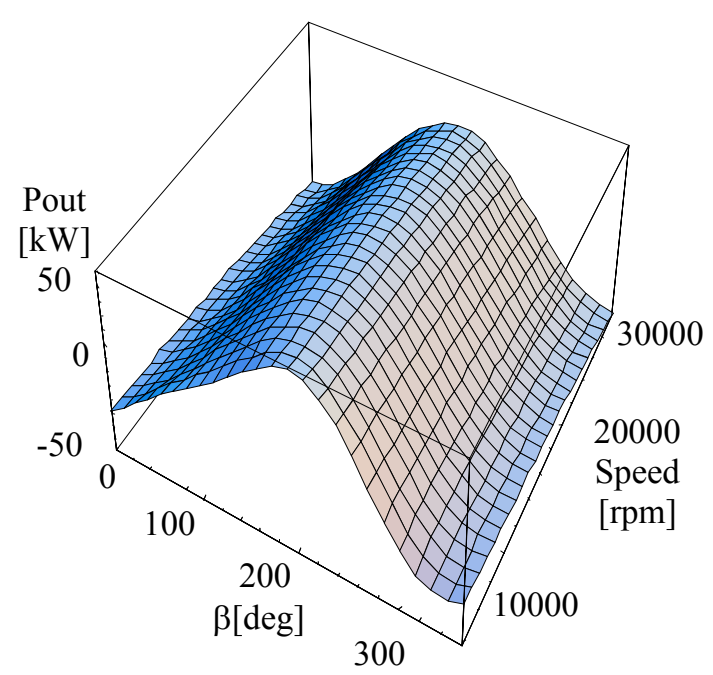

(a) With grid.

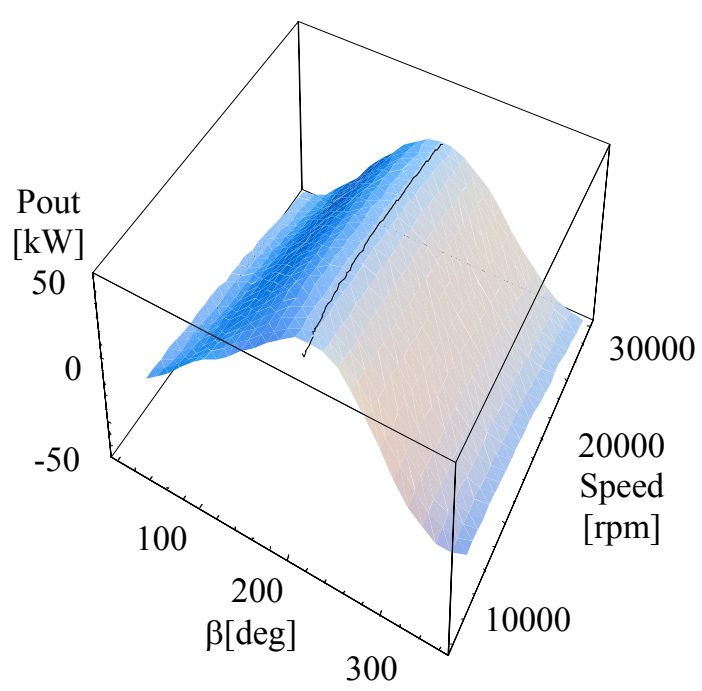

(b) With optimal-power trajectory superimposed.

Fig. 8. Power output as a function of speed for the full range of voltage-control angles for Motor X.

The maximum power versus speed curve is shown in Fig. 9 for the voltage-limited region and the values of the voltage-phase angle, $\beta$, necessary to maximize Eq. (43) are shown in Fig. 10. For this motor, the optimal $\beta$ starts at about $206^{\circ}$ at the base speed of 3700 mechanical rpm and shifts towards $180^{\circ}$ as the speed increases.

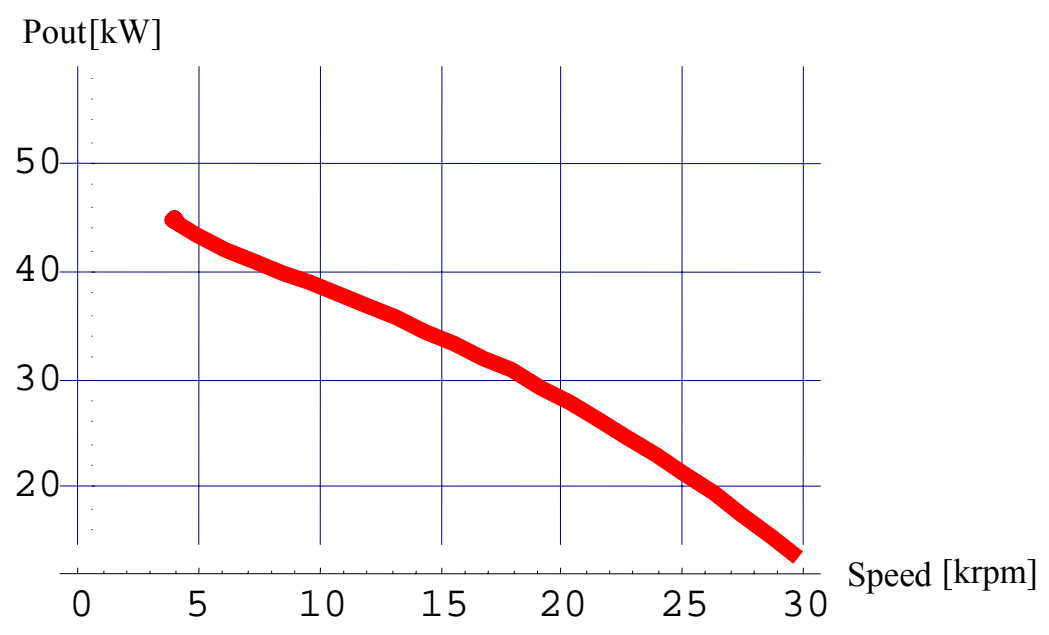

Fig. 9. Optimal-power output as a function of speed for Motor X. 


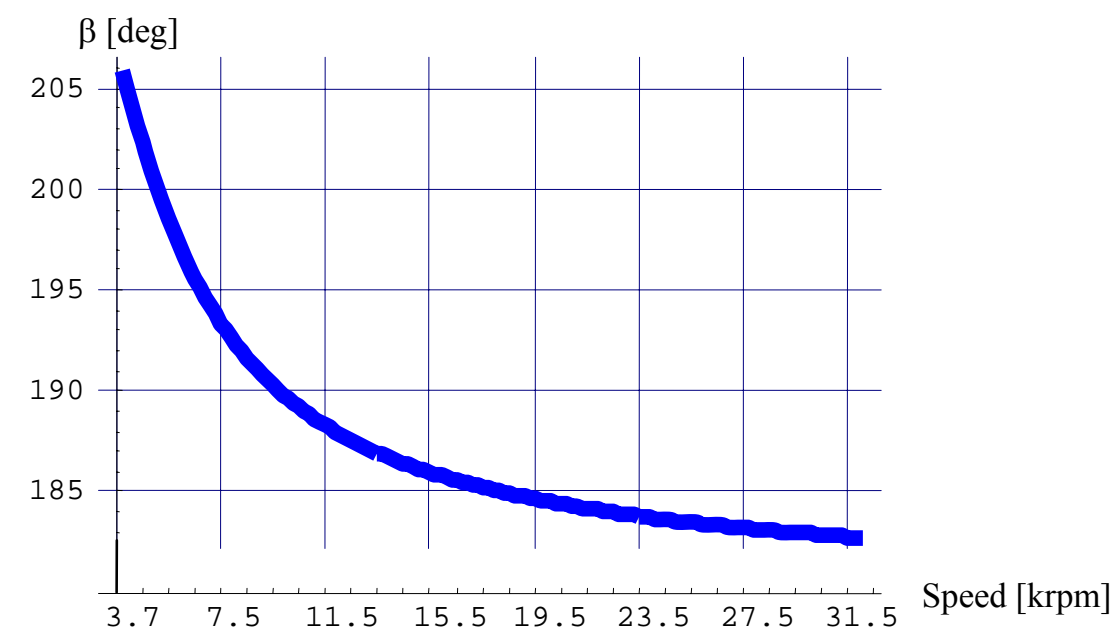

Fig. 10. Voltage-phase angle, $\beta$, required to obtain maximum-power output above base speed as a function of speed for Motor X.

In the following section a simpler example of optimization will be examined for illustration.

\subsection{A MORE TRACTABLE RELATION FOR MAXIMUM POWER UNDER CURRENT CONTROL IN THE CURRENT-LIMITED REGION}

Following the methodology of Section 2.5, an expression for $P_{\text {out }}\left(I_{t}, \gamma\right)$ similar to Eq. (43) may be derived. In the current-limited region below base speed, the optimal-current angle, $\gamma$, may be obtained by substituting $\mathrm{I}_{\mathrm{t}}=\mathrm{I}_{\max }$ in $P_{\text {out }}\left(I_{t}, \gamma\right)$ and finding the value of $\gamma$ for which $\partial P_{\text {out }} / \partial \gamma=0$.

Below base speed, the expressions for optimal $\gamma$ are more tractable than those for optimal $\beta$ above base speed given in Section 2.5. The expression for the optimal-current-phase angle, $\gamma_{c l}$, in the current-limited region is

$$
\gamma_{\mathrm{cl}}=\operatorname{ArcCos}\left(\frac{\mathrm{L}_{\mathrm{mb}}-\sqrt{8(\xi-1)^{2} \mathrm{Ld}^{2}+\mathrm{L}_{\mathrm{mb}}{ }^{2}}}{4 \mathrm{Ld}(\xi-1)}\right)=\operatorname{ArcCos}\left(\frac{\mathrm{M}_{1}}{\mathrm{M}_{2}}\right)
$$

and the corresponding maximum power is

$$
P_{\text {out } \_c l}=\frac{3}{2} I_{\max } \omega_{e}\left(\lambda_{m}-I_{\max } L d(\xi-1) \frac{M_{1}}{M_{2}}\right) \sqrt{1-\frac{M_{1}^{2}}{M_{2}^{2}}}-P_{F e}
$$

where $M_{1}$ and $M_{2}$ are the numerator and denominator in Eq. (40).

The power for the optimal-current angle, $\gamma_{c l}$, in the current-limited region is plotted as a function of speed using Eqs. (45) and (46) in Fig. 11 for Motor X. Its corresponding torque is constant and equal to $188 \mathrm{~N}-\mathrm{m}$. 


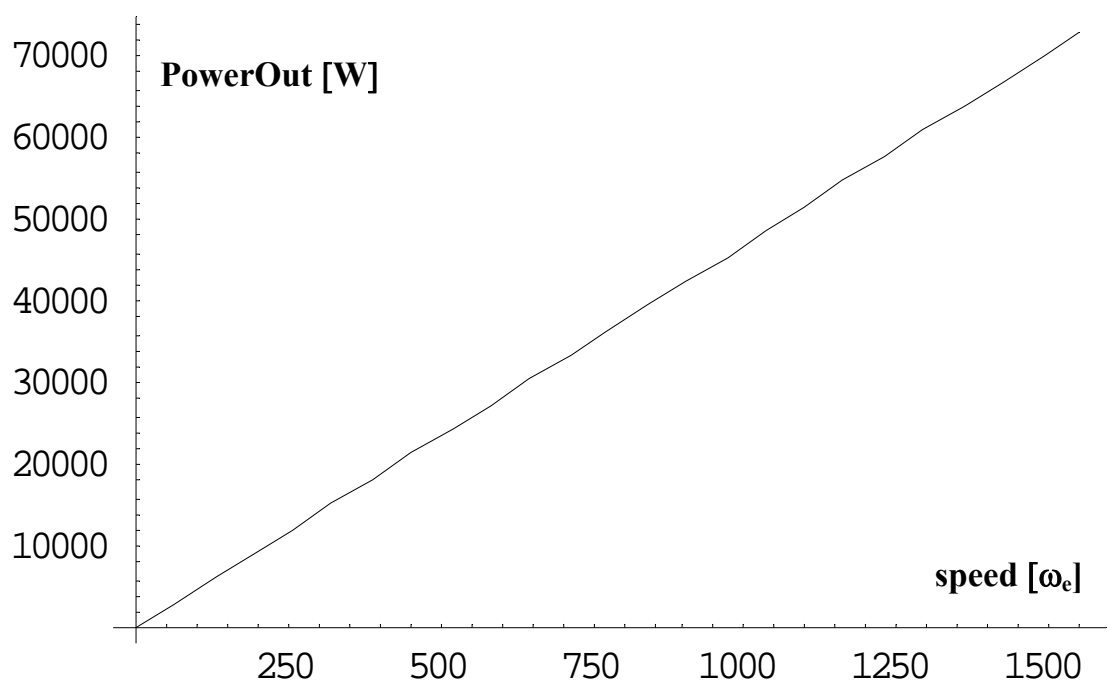

Fig. 11. Maximum-power output in the current-limited region below base speed for Motor $\mathrm{X}$.

The optimal-current angle and torque in the current-limited region are plotted as a function of saliency using Eqs. (45) and (46) in Figs. 12(a) and (b) for a motor with all other parameters except saliency equal to those of Motor X.

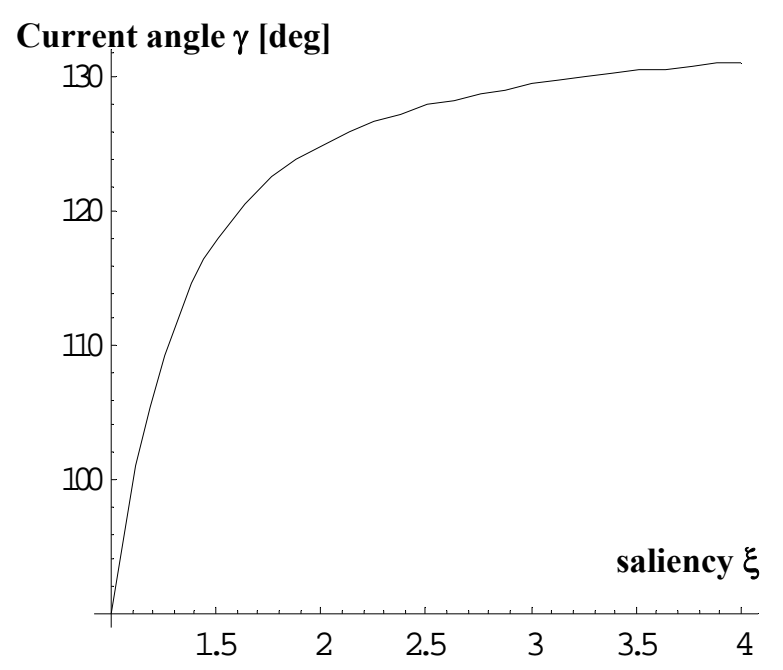

(a) Optimal-current angle, $\gamma$.

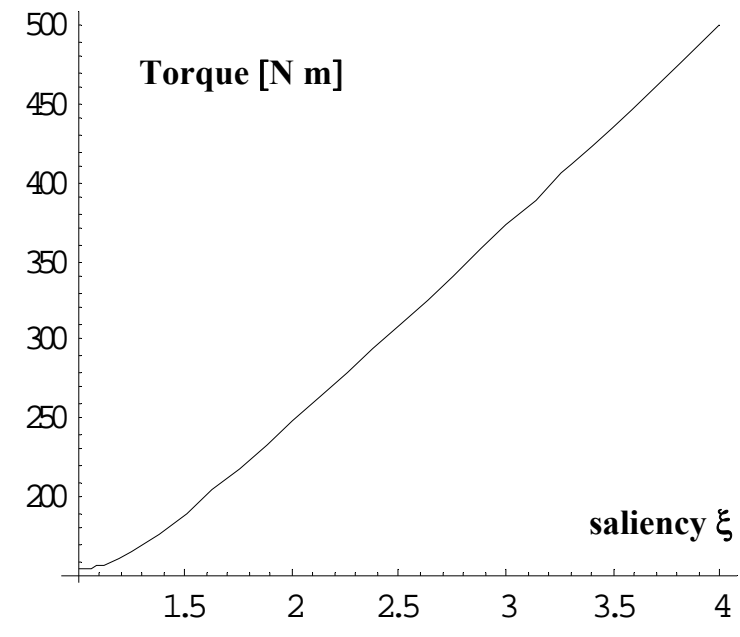

(b) Torque.

Fig. 12. Maximum-power output trajectories below base speed in the current-limited region for Motor X-like motors with saliencies from one to four. 


\section{MAXIMIZING PERFORMANCE OF A MOTOR WITH SALIENCY: OPTIMAL-MAGNET FRACTION}

In the LabVIEW model, the fundamental Eqs. (24-30) are solved iteratively to find the optimal-current or voltage angles required to obtain (a) maximum-power output and (b) maximum efficiency all along the operating envelope of the motor, over both the current-limited and voltage-limited regions. The corresponding currents, voltages, and reluctance factors are also computed.

The model has been applied to study the impact of reluctance in reluctance-assisted PM motors. Taking as input data, the dependence on the amount of PM material of the fundamental-lumped parameters $\mathrm{L}_{\mathrm{d}}, \mathrm{L}_{\mathrm{q}}$, and $\lambda_{\mathrm{m}}$ in an inset PM motor, LabVIEW computes the maximum power and efficiency for each configuration. External loops have been added to the base-model to perform addition studies, such as the impact of using weaker PM material which corresponds to the loss of magnetic strength.

Figures 13(a) and (b) show how the fundamental parameters vary for the inset PM motor as a function of the magnet's angular pitch. The iron's angular pitch shrinks as the magnet grows since both add up to $180^{\circ}$. Figure 13(a) shows the values of $\mathrm{L}_{\mathrm{d}}, \mathrm{L}_{\mathrm{q}}$, and $\lambda_{\mathrm{m}}$. Note that the maximum difference between $\mathrm{L}_{\mathrm{q}}$ and $\mathrm{L}_{\mathrm{d}}$ occurs at $90^{\circ}$ and that above $130^{\circ}$ there is practically no gain in $\lambda_{\mathrm{m}}$. Figure $13(\mathrm{~b})$, which is derived from Fig. 13(a), shows the saliency ratio peaking at $130^{\circ}$ while the characteristic current peaks near $160^{\circ}$.

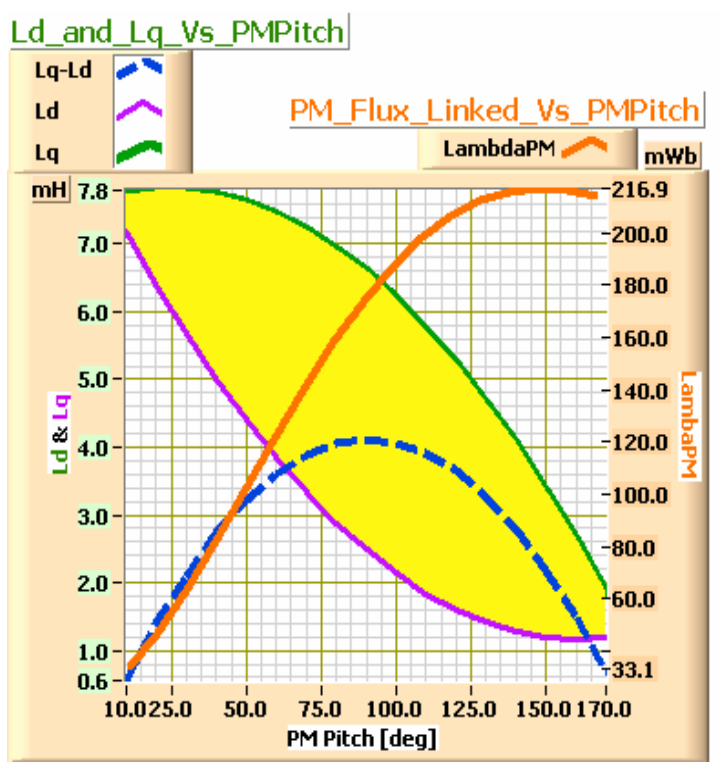

(a) Values of $L_{d}, L_{q}$, and $\lambda_{m}$.

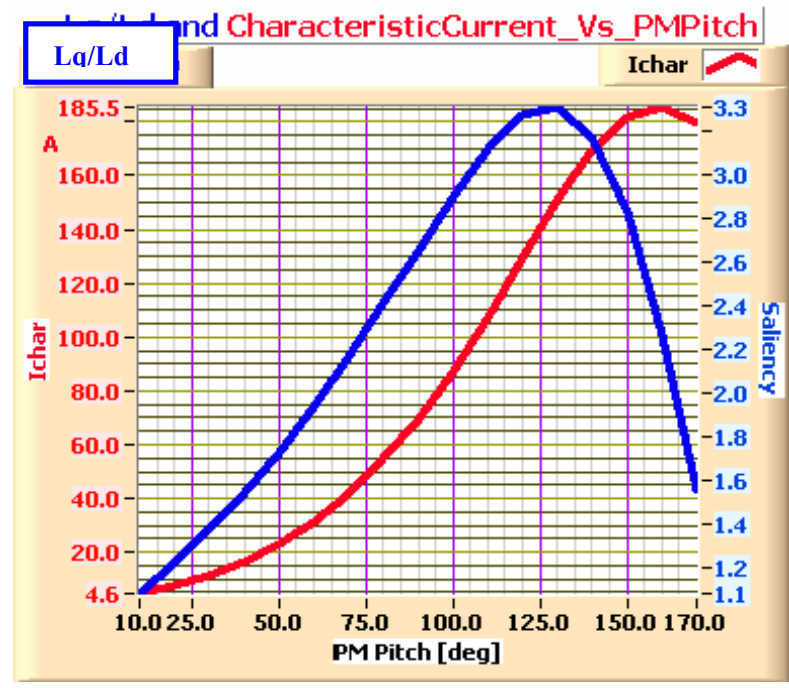

(b) Saliency ratio and characteristic current.

Fig. 13. Dependence of the fundamental parameters on the magnet's angular pitch.

First, let us look at the case in which the PM occupies $170^{\circ}$ of the $180^{\circ}$ available. This has a small degree of saliency $(\xi=1.5$ per Fig. 13(b)) and corresponds to an inset PM motor with minimum separation between the PMs as in case Fig. 2(b). The maximum power attainable at each speed and its efficiency are shown in Figs. 14(a) and (b) for different strengths of the PM material. 


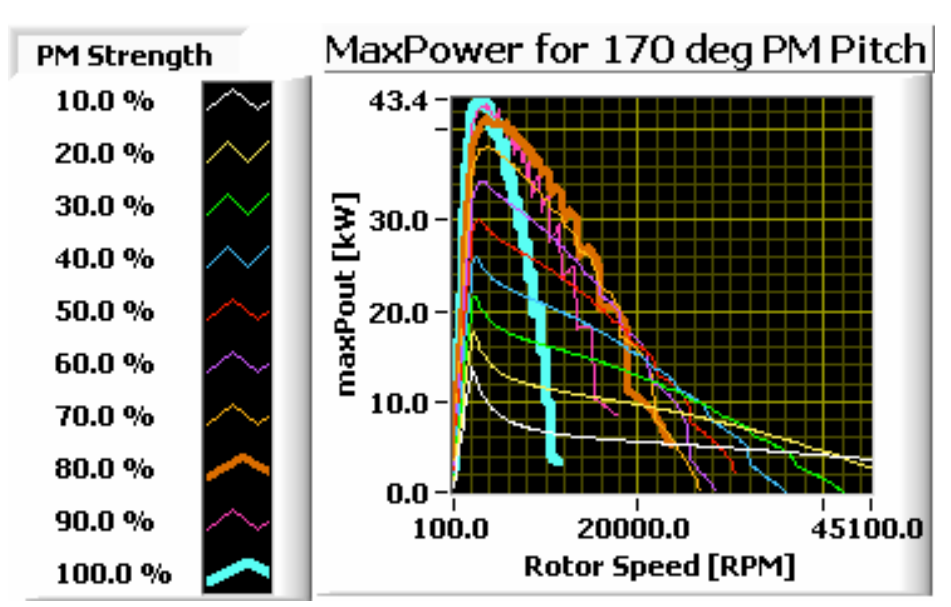

(a) Maximum-output power.

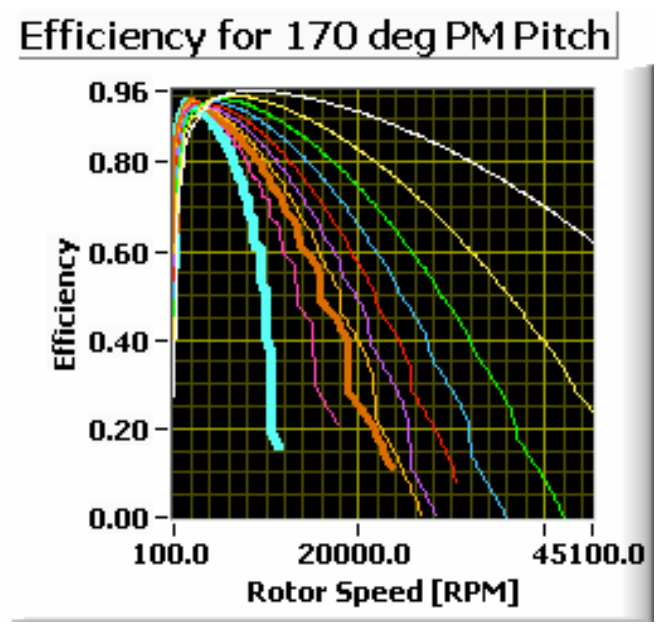

(b) Efficiency for the maximum power.

Fig. 14. Dependence of performance on the magnet's strength for $170^{\circ} \mathrm{PM}$ pitch.

Since the speed iteration is stopped during the iterative computations as soon as the efficiency becomes negative, the curves for different PM strength and also those for different PM angular pitch have different ranges.

The thick blue lines in Fig. 15 show that at full PM strength this motor has the highest power-output peak, but its power output decays rapidly with speed. Its speed range is shorter and its efficiency at high speeds is smaller than motors with weaker PM material.

Figures 15(a) and (b) are zoomed-in versions of Fig. 14. For this angular pitch, magnets with $80 \%$ strength that are represented by thick purple lines, double the speed range and have better efficiency at high speeds with little loss of peak power.

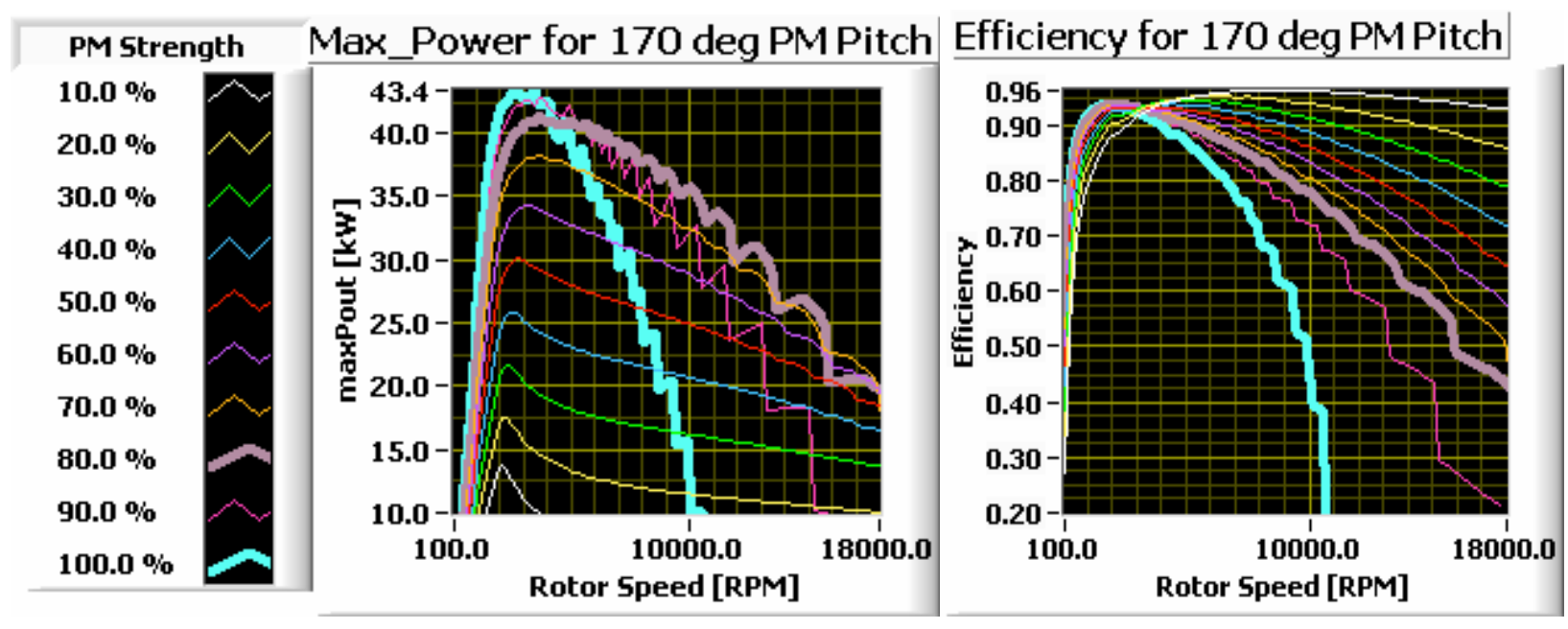

(a) Maximum-output power.

(b) Efficiency for the maximum power.

Fig. 15. Zoom-in of Fig. 14. 
On the other hand, if one looks at the dependence on PM angular pitch for a full strength PM in Figs. 16(a) and (b), the orange line corresponding to a $130^{\circ}$ pitch seems preferable to the $170^{\circ}$ blue lines in terms of speed range and efficiency at high speeds. The zoomed versions in Figs. 17(a) and (b) confirm that even at low speeds in the current-limited region, the $130^{\circ} \mathrm{PM}$ pitch is a better option in terms of both power output and efficiency. This value of the pitch angle coincides with the peak in the saliency ratio of 3.3 shown in Fig. 13(b).

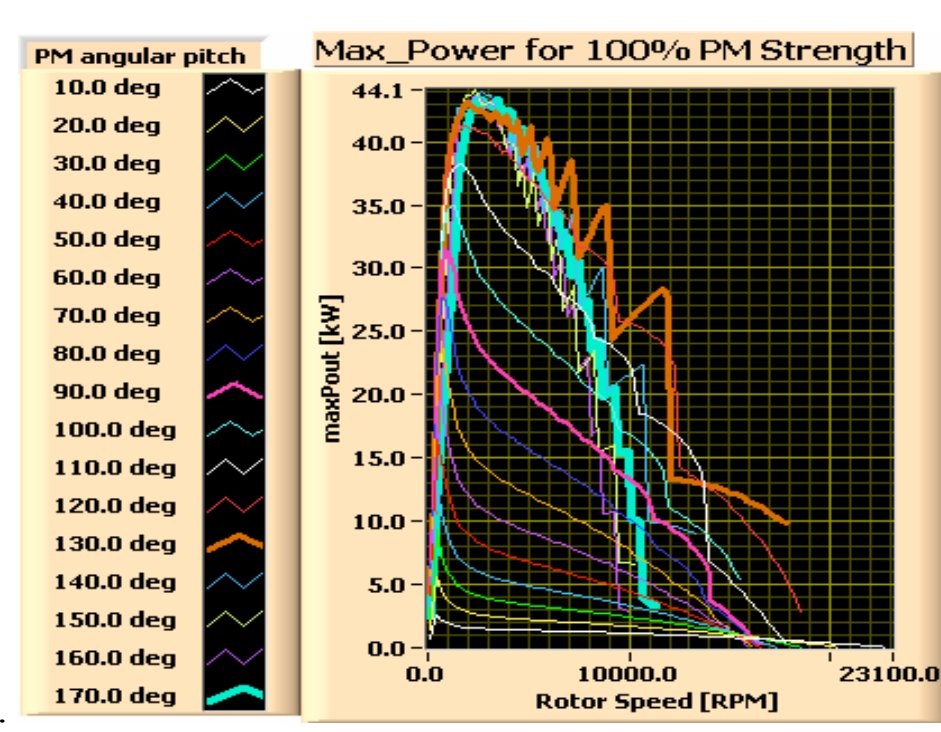

(a) Maximum-output power.

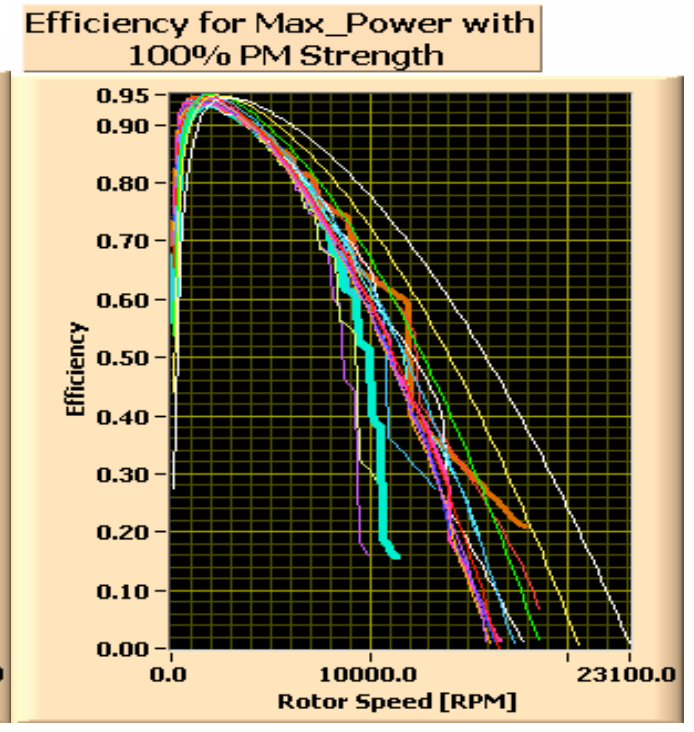

(b) Efficiency for the maximum power.

Fig. 16. Speed dependence of optimal performance on the PM pitch angle at $100 \%$ magnet strength.

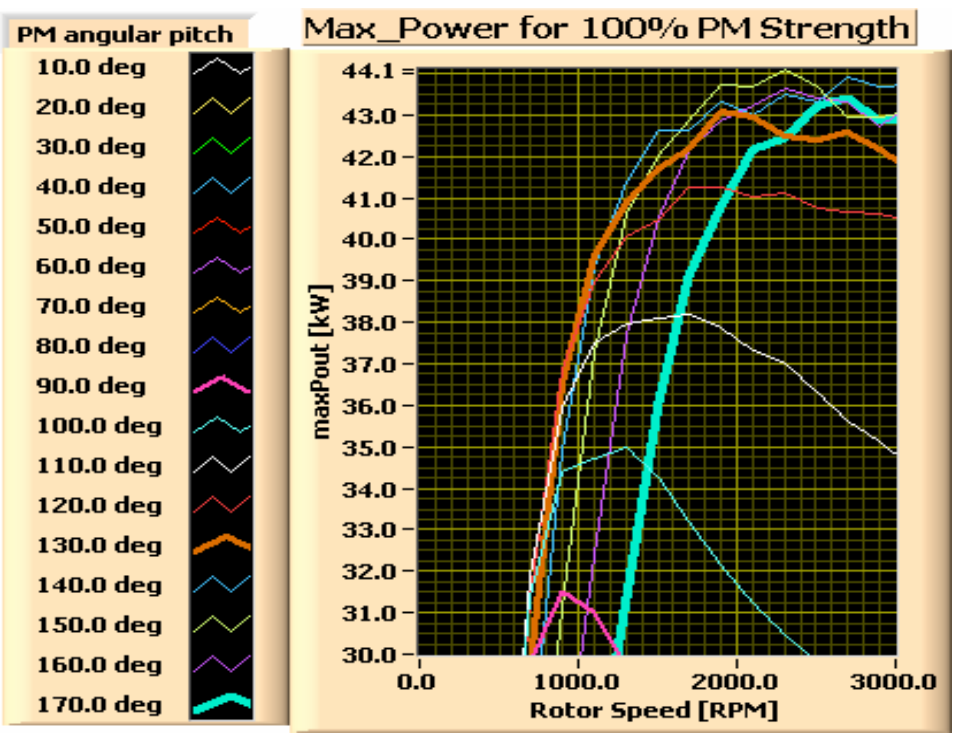

(a) Maximum-output power.

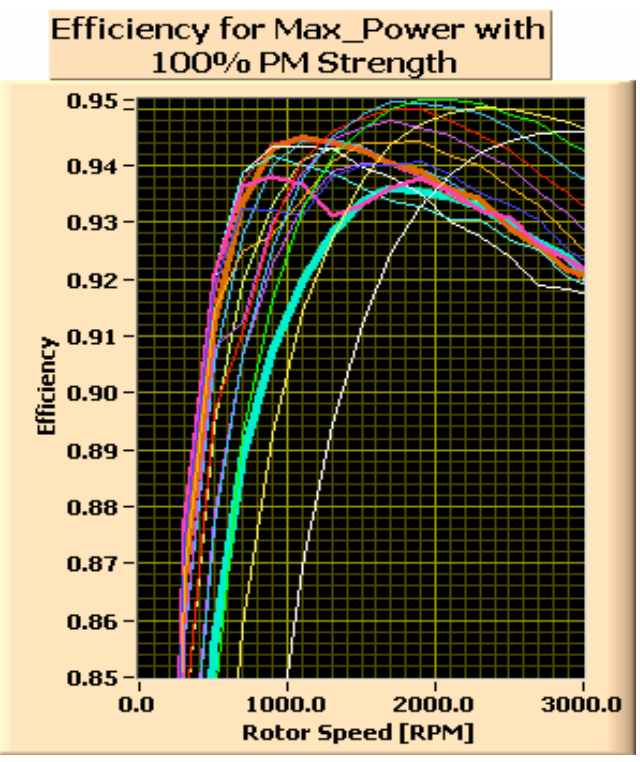

(b) Efficiency for the maximum power.

Fig. 17. Zoom-in of Fig. 16. 
We look now at the $130^{\circ}$ PM pitch angle in Figs. 18(a) and (b) and, comparing the $100 \%$ PM strength blue line with the rest, we see that using magnetic material of $80 \%$ magnetic strength (orange line) may still be desirable because of higher efficiency.

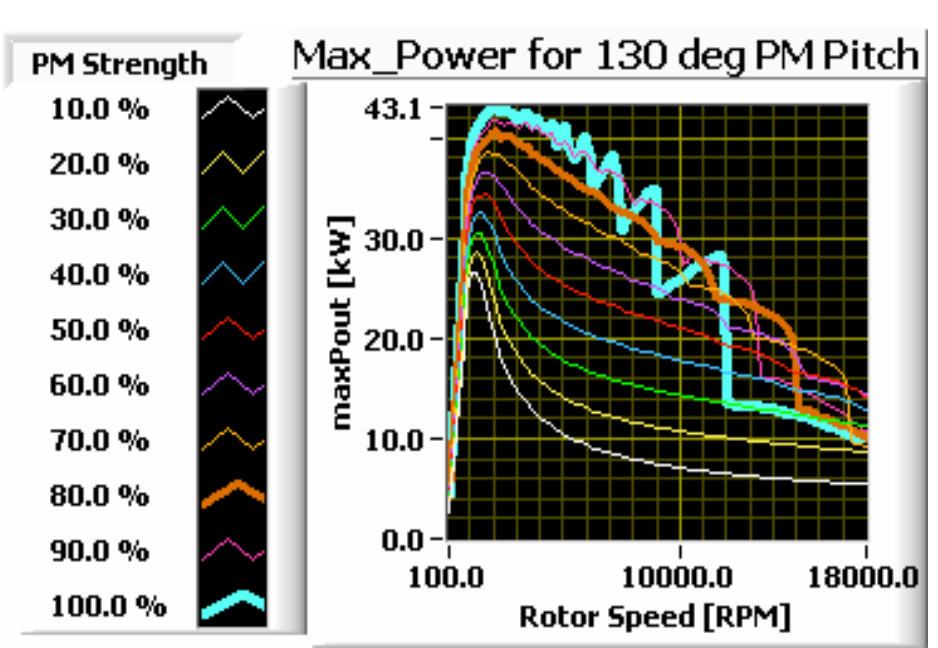

(a) Maximum-output power.

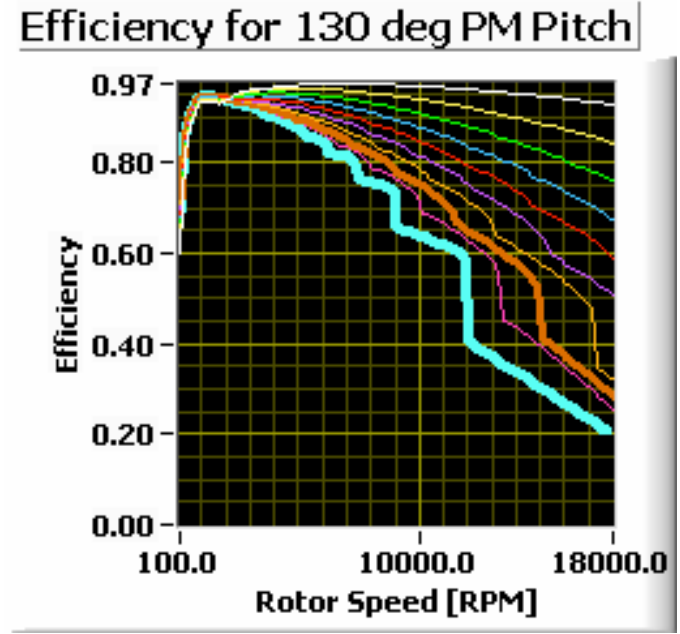

(b) Efficiency for the maximum power.

Fig. 18. Speed dependence of optimal performance on the magnet's strength for a $130^{\circ} \mathrm{PM}$ pitch angle.

For $80 \%$ magnetic strength, Figs. 19 (a), (b), 20(a) and (b) favor $150^{\circ}$ pitch. The optimal-PM angle is dependent on the magnet strength but stays in the $130-170^{\circ}$ region where the peak values of the characteristic current and the saliency factor are found in Fig. 13(b). Yet, at low speeds up to $40 \mathrm{~kW}$, the $130^{\circ}$ is better even at $80 \%$ magnet strength. The best choice will ultimately depend on the time the motor is operated in the speed/power out map.

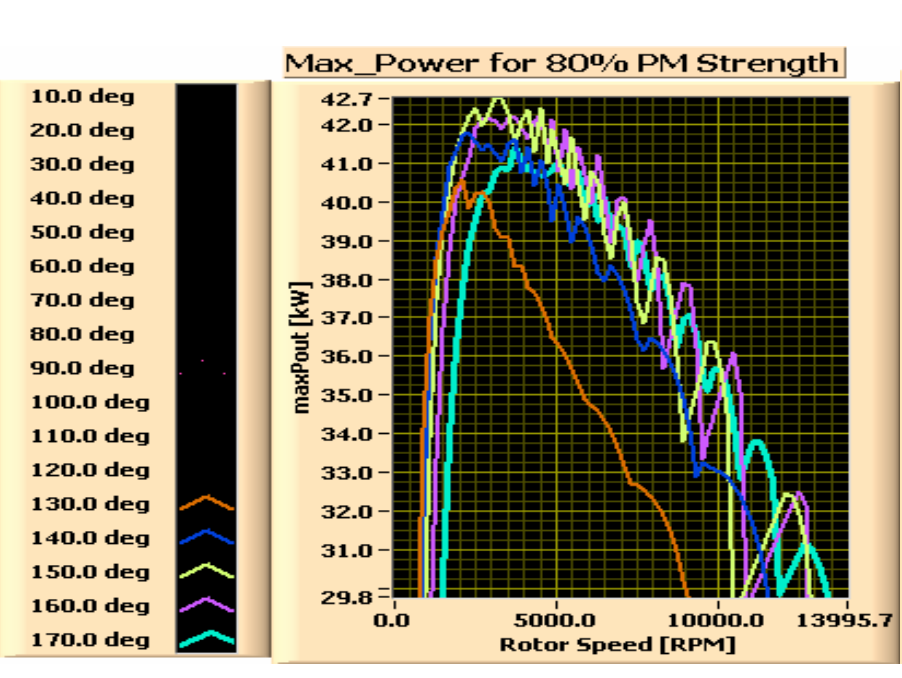

(a) Maximum-output power.

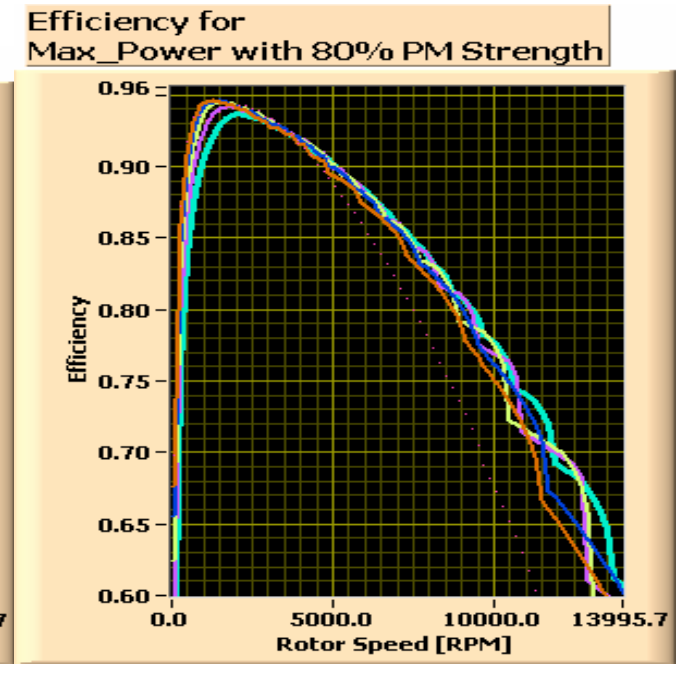

(b) Efficiency for the maximum power.

Fig. 19. Speed dependence of optimal performance on the PM pitch angle for $80 \%$ PM strength. 


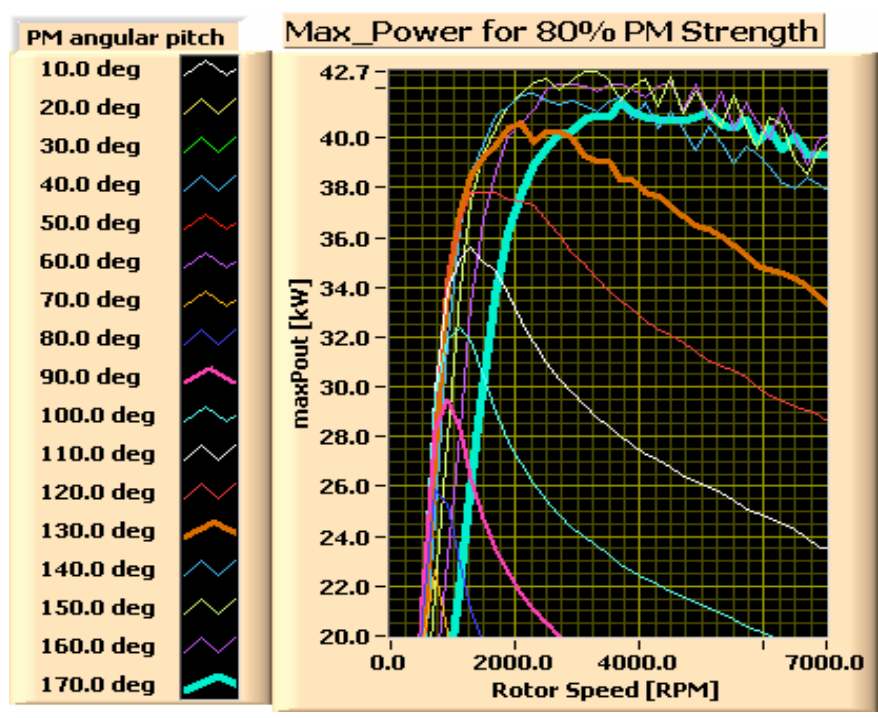

(a) Maximum-output power.

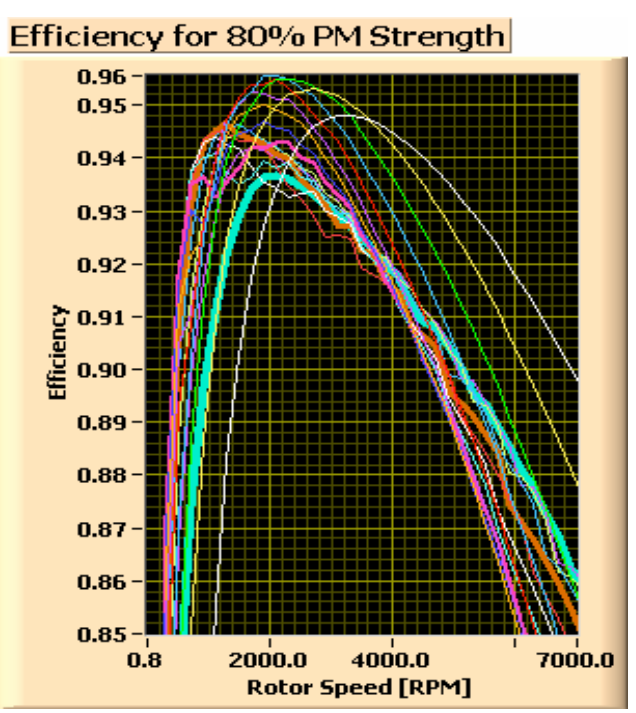

(b) Efficiency for the maximum power.

Fig. 20. Zoom-in of Fig. 19.

We now look at Figs. 21(a) and (b) corresponding to a magnet fraction of 0.5 , which has a $90^{\circ} \mathrm{PM}$ pitch angle and where the difference between $\mathrm{L}_{\mathrm{q}}$ and $\mathrm{L}_{\mathrm{d}}$ is the maximum in Fig. 13(a). The power levels are much lower primarily because there is half as much PM material. The relative contribution of reluctance torque to total torque for $90^{\circ}$ and $130^{\circ} \mathrm{PM}$ pitch angles are shown in Figs. 22(a) and (b), respectively, as a function of PM magnet strength. For both pitch angles, the reluctance fraction increases with speed in the current-limited region up to the peak which occurs at the base speed and declines with speed in the voltage-limited region. Their reluctance-fraction peaks are similar, but the rate of decrease is slower for the case where the PM pitch is $130^{\circ}$. For $100 \%$ magnet strength and $130^{\circ} \mathrm{PM}$ pitch, the reluctance fraction remains almost constant in the voltage-limited region as shown in Figs. 22(b).

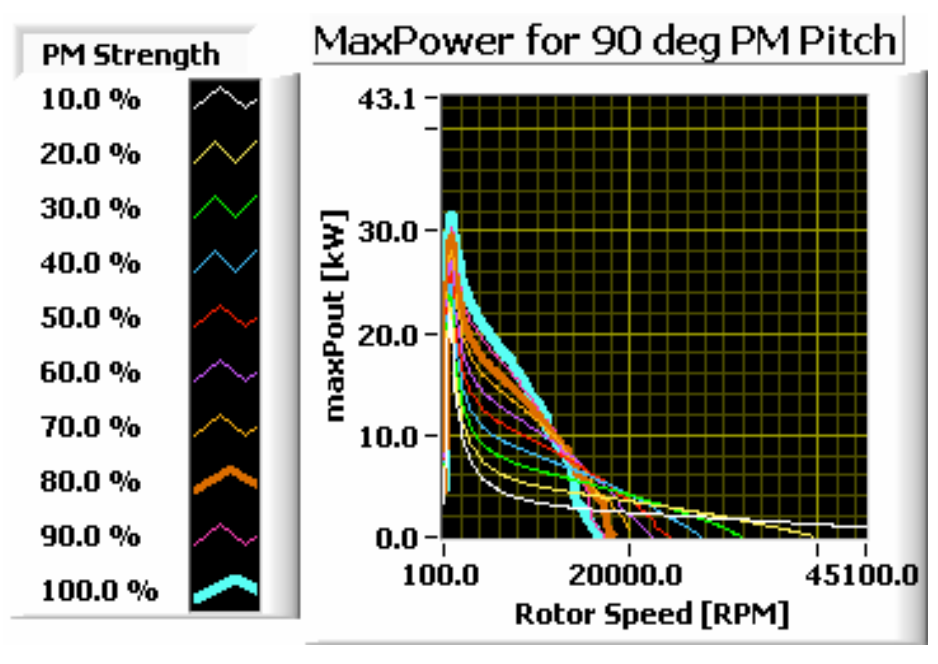

(a) Maximum-output power.

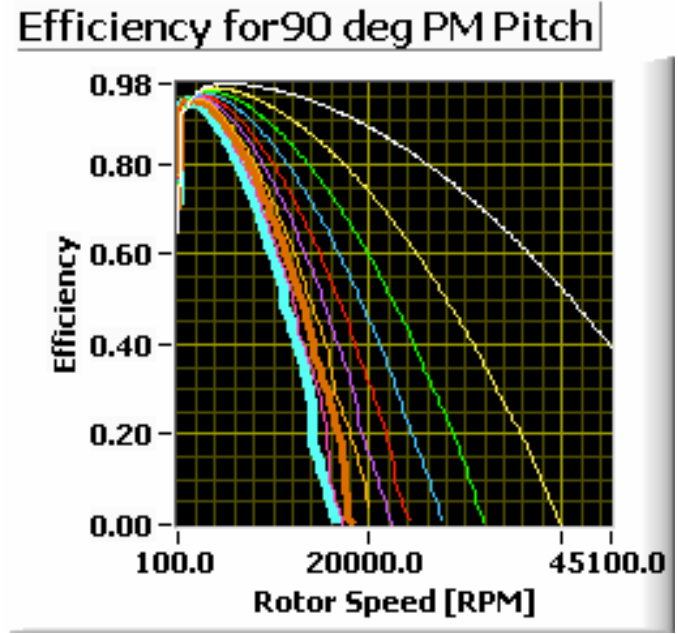

(b) Efficiency for the maximum power.

Fig. 21. Speed dependence of optimal performance on the magnet's strength for $90^{\circ} \mathrm{PM}$ pitch angle. 


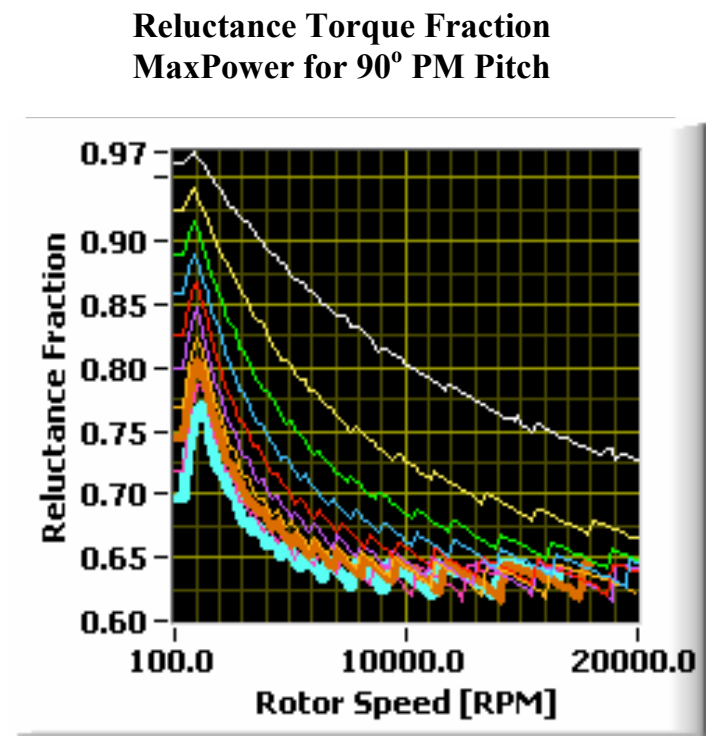

(a) For $90^{\circ} P M$ pitch $\left(\max L_{q}-L_{d}\right)$.
Reluctance Torque Fraction

MaxPower for $1^{\circ} 0^{\circ}$ PM Pitch

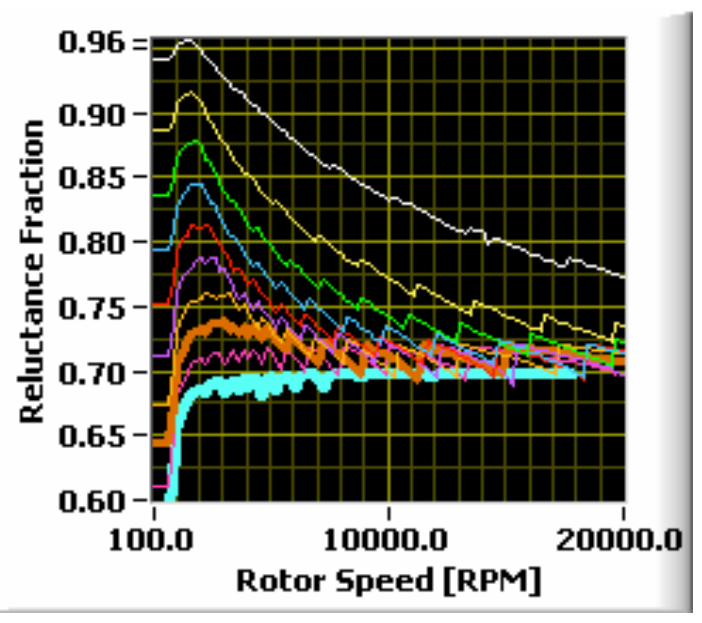

(b) For $130^{\circ} P M$ pitch $\left(\max \mathbf{L}_{q} / \mathbf{L}_{d}\right)$.

Fig. 22. Comparison of the speed dependence of the reluctance-torque fraction on the magnet's strength for a magnet fraction of 0.5 and a magnet fraction of 0.72 .

\subsection{OPTIMAL-MAGNET FRACTION BASED ON STEADY-STATE CALCULATIONS}

Simply based on the steady-state operating curves, the optimal-PM pitch angle is $130^{\circ}$, which corresponds to a magnet fraction of 0.72 . For the PM pitch of $130^{\circ}$, the optimal strength of the PM magnet also seems to be between $80 \%$ and $100 \%$ of the original strength; conversely, if one first selects a magnet strength of $80 \%$, then the optimal-PM pitch moves toward $150^{\circ}$.

For completeness, we show in Figs. 23(a-d) the speed dependence on magnet strength of current, optimal-current-phase angle, terminal voltage, and optimal voltage-phase angle all at maximum power delivery for the $130^{\circ} \mathrm{PM}$ pitch-angle design. The reluctance-torque fraction has already been shown in Fig. 22(b). Also, Figs. 24(a-e) show the speed dependency on PM pitch angle of current, optimalcurrent-phase angle, terminal voltage, optimal voltage-phase angle, and reluctance-torque fraction all for maximum power delivery for the design using $80 \%$ magnet strength. 


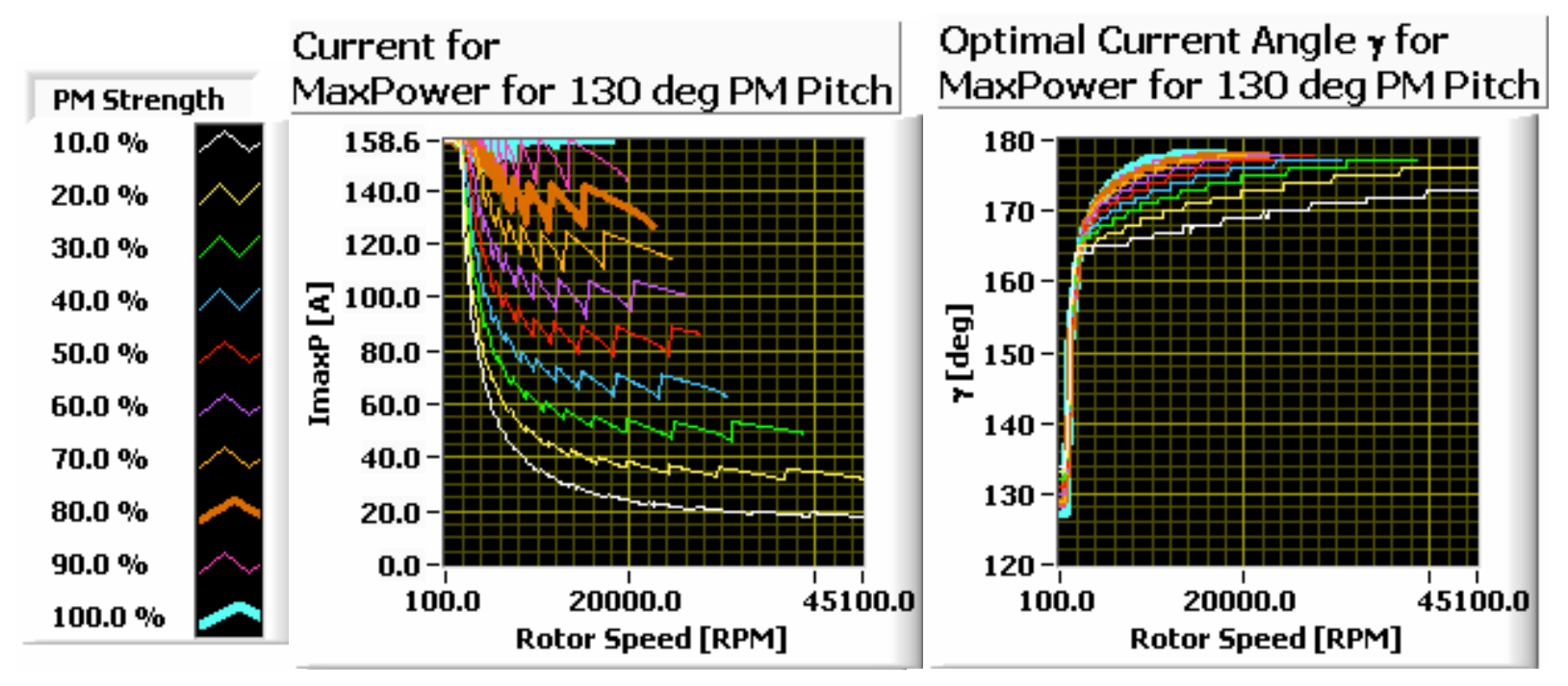

(a) Current for maximum power.

(b) Current-phase angle for maximum power.

Effective voltage for

PM Strength MaxPower for 130 deg PMPitch $10.0 \%$

$20.0 \%$

$30.0 \%$

$40.0 \%$

$50.0 \%$

$60.0 \%$

$70.0 \%$

$80.0 \%$

$90.0 \%$

$100.0 \%$
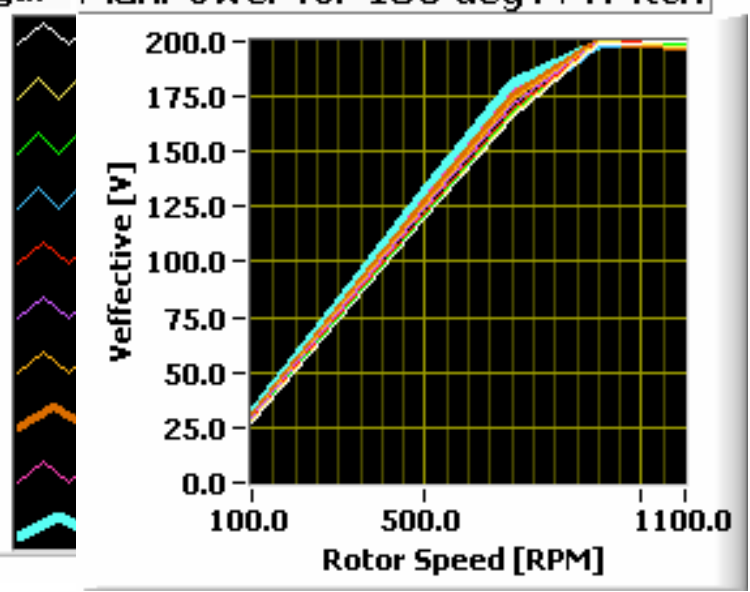

(c) Terminal voltage for maximum power.

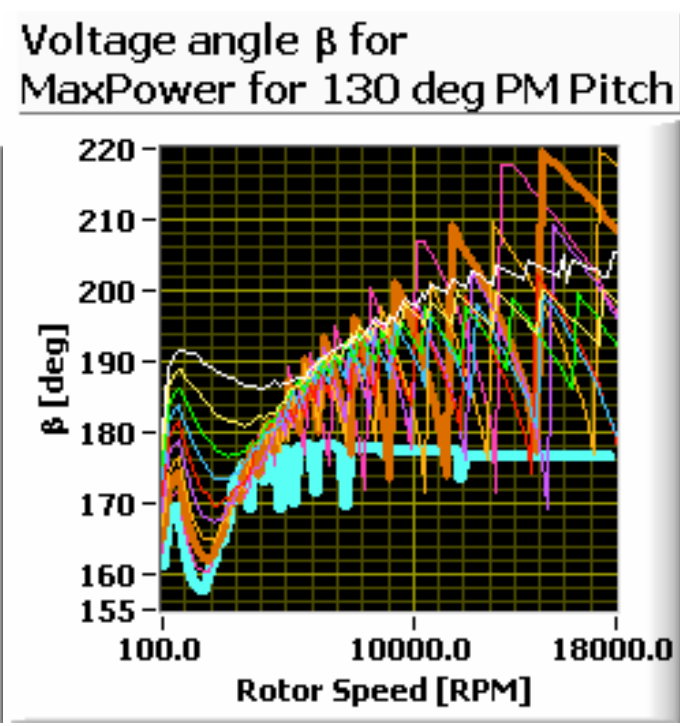

(d) Voltage-phase angle for maximum power.

Fig. 23. Speed dependence of optimal parameters on percent PM strength for $130^{\circ} \mathrm{PM}$ pitch angle. 


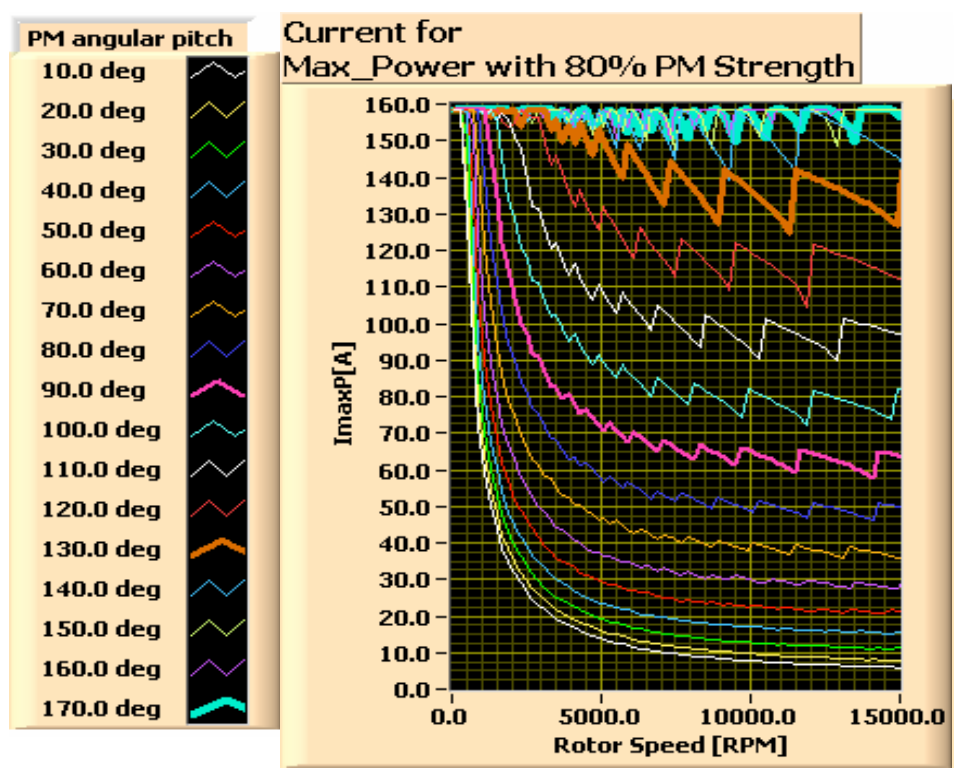

(a) Current for maximum power.

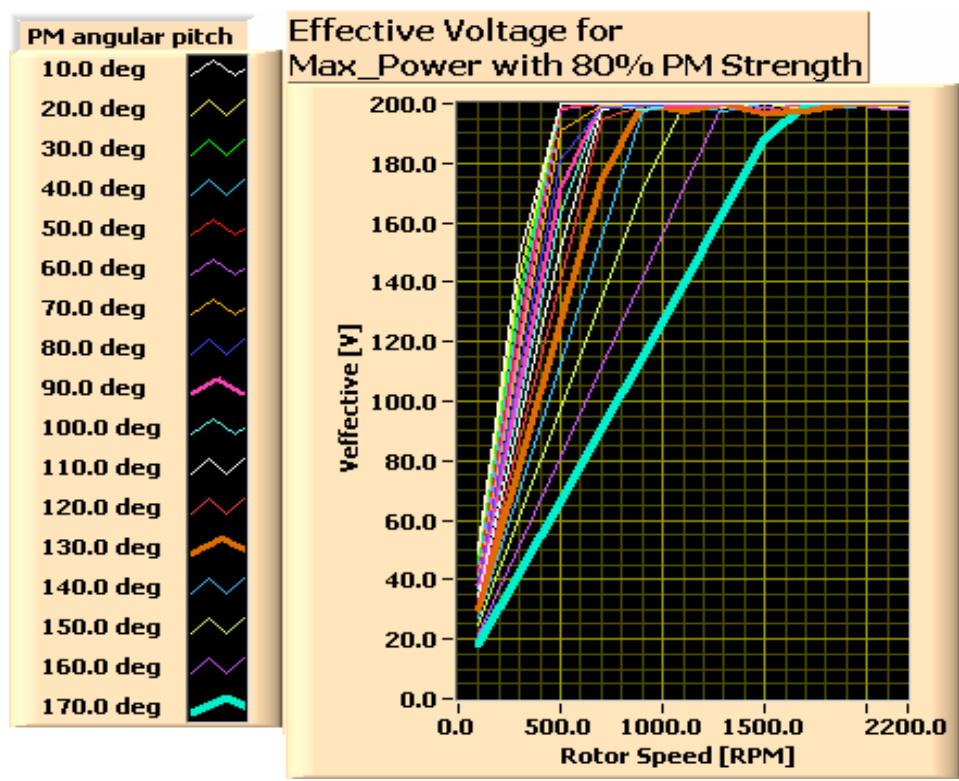

(c) Terminal voltage for maximum power.
Optimal Current Angle for

Max_Power with 80\% PM Strength

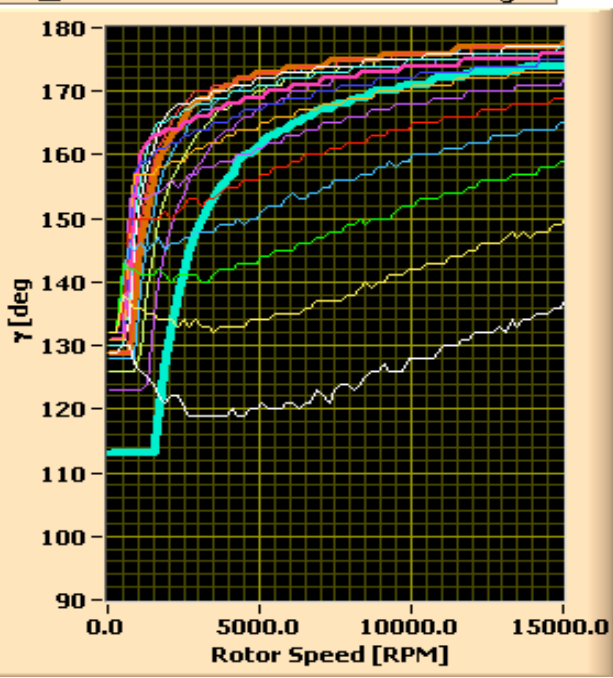

(b) Current-phase angle for maximum power.

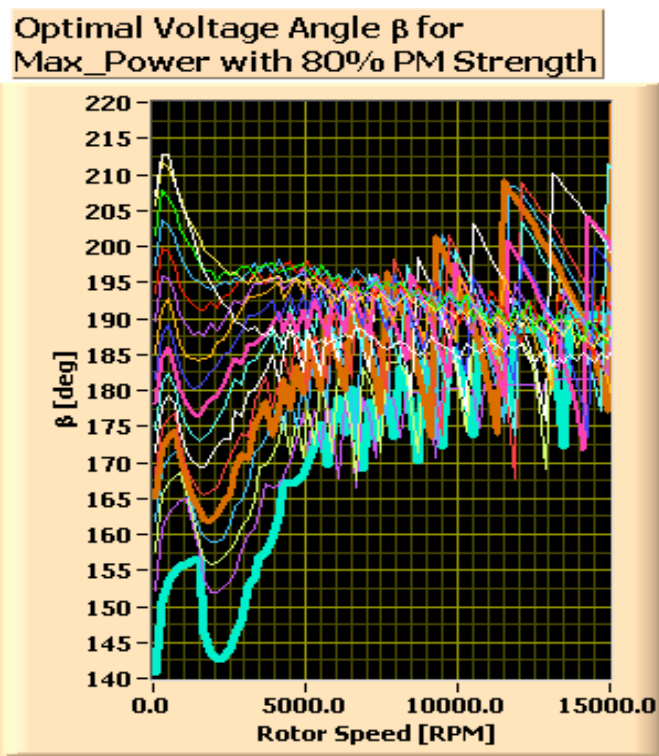

(d) Voltage-phase angle for maximum power.

Fig. 24. Speed dependence of optimal parameters on PM pitch angle for $80 \%$ magnet strength. 


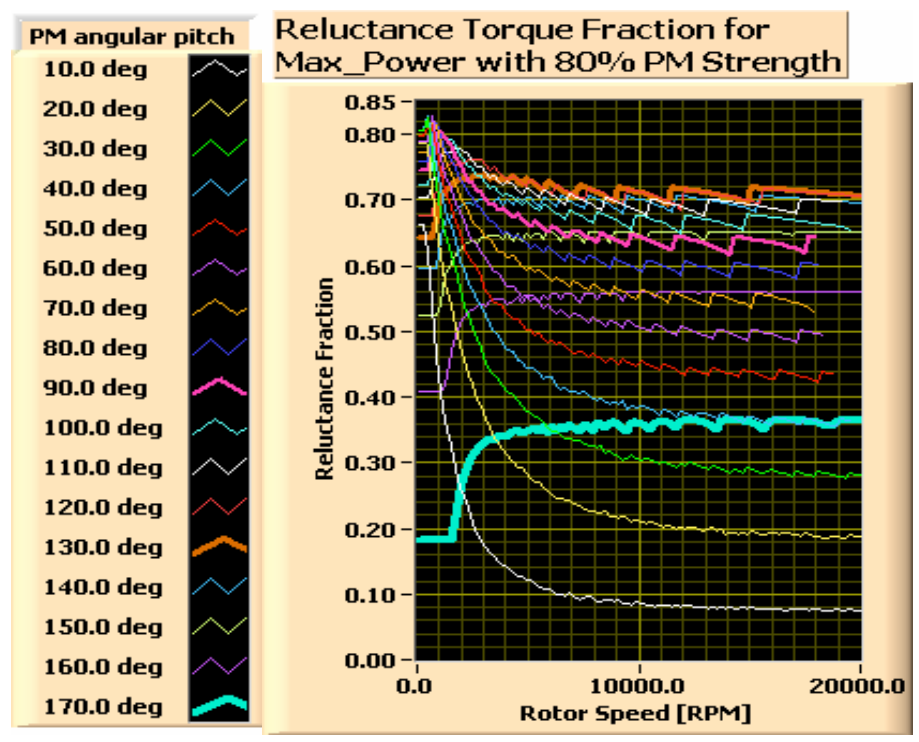

(e) Reluctance-torque fraction for maximum power.

Fig. 24. Speed dependence of optimal parameters on PM pitch angle for $80 \%$ magnet strength (cont'd).

\subsection{OPTIMIZATION CONSIDERING ACTUAL LIFETIME OPERATING CYCLES}

Selection of the optimal reluctance-assisted PM motor configuration should not be based only on the steady-state performance curves. The anticipated lifetime operating cycle should also be considered. For hybrid electric vehicles (HEVs), examples of two such standard operating cycles that represent urban and highway driving averages are shown in Figs. 25(a) and (b). The speed versus time trace of the Federal Urban Driving Schedule (FUDS) includes frequent stops and limited operation above $40 \mathrm{mph}$. In the Federal Highway Driving Schedule (FHDS) there are no intermediate stops and the speed is seldom below $40 \mathrm{mph}$. The electric traction motor's speed is directly related to the vehicle's speed; thus, the driving cycle characterizes trajectories in the electric motor's efficiency and power maps. The overall efficiency thus depends on the driving cycle. In addition, consideration of regeneration during braking is important especially when the cycle includes frequent decelerations.

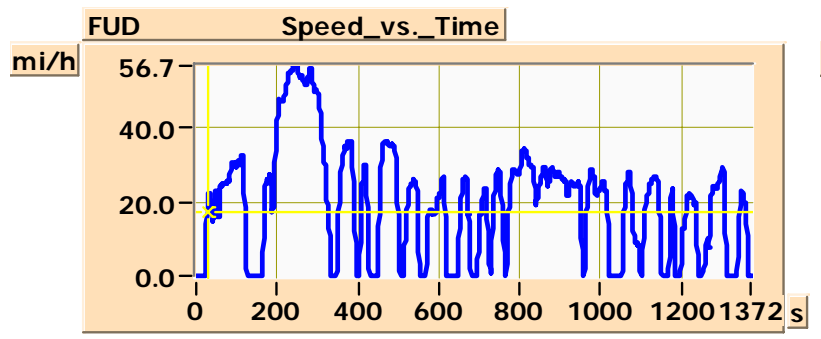

(a) Federal urban driving cycle.

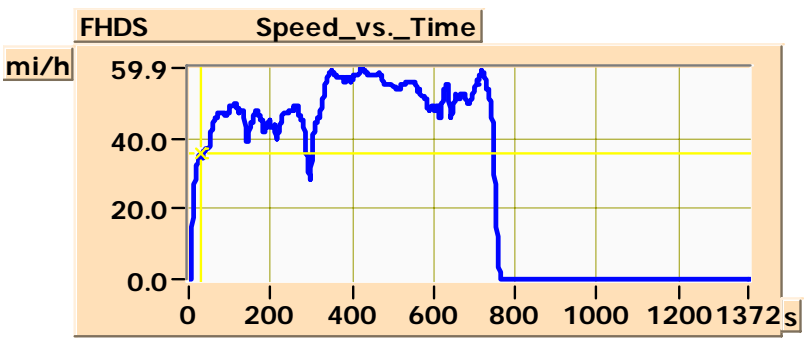

(b) Federal highway driving cycle.

Fig. 25. Typical driving schedules.

For a particular driving cycle, the mass of the vehicle, its passenger and load, tire inflation, and aerodynamic-wind resistance are important contributors to determine power required. Figures 26(a) and (b) show the power-requirement maps associated with the two driving cycles of Figs. 25. When there is no regeneration, only the parts of the curves above the zero line are considered. The same power demand 
information is shown in Figs. 27(a) and (b), this time in terms of motor speed in rpm corresponding to the linear velocity of the vehicle.

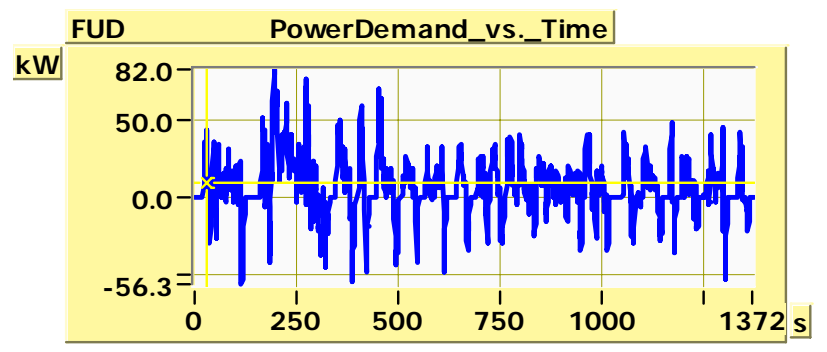

(a) FUDS.

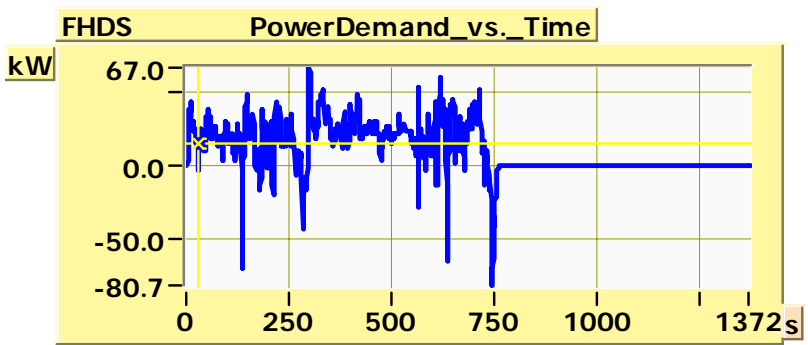

(b) FHDS.

Fig. 26. Typical power demand vs. time for standard-driving schedules.

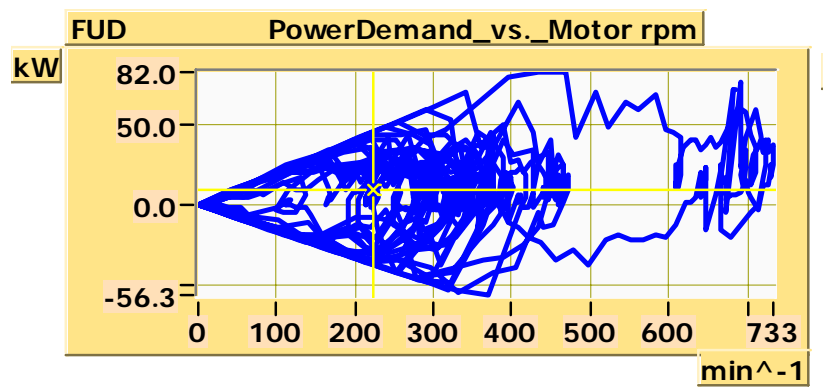

(a) FUDS.

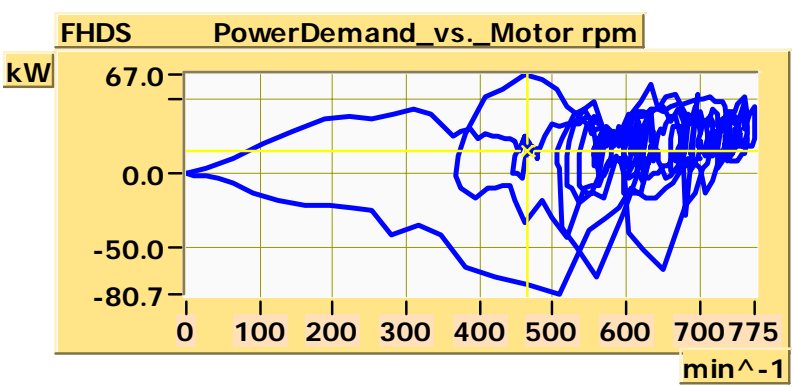

(b) FHDS.

Fig. 27. Typical power demand vs. motor speed for standard-driving schedules.

In conclusion, the ultimate selection of an optimal design in this case of optimal-PM fraction in this inset PM motor could benefit by including a driving-cycle-weighted efficiency. Low efficiencies at peaktorque conditions may be acceptable when the percentage of time spent at those conditions is small. 


\section{CONCLUSIONS}

The conclusions will address, among other observations, the key research subjects introduced in Chapter 1 of this report and related to modeling reluctance-assisted PM motors. The questions were:

(1) How does reluctance torque improve the performance in a reluctance-assisted PM motor?

(2) What can a reluctance-assisted PM motor do that a PM motor cannot do by itself?

(3) What are the equations used to model the reluctance-assisted PM motor?

(4) How are the effects of magnetic saturation modeled for a reluctance-assisted PM motor?

(5) What is the criterion that should be used to define optimum performance?

(6) Once optimum performance is defined, how is the optimum magnet fraction determined?

1. Reluctance torque improves the performance of a reluctance-assisted PM motor by adding a component of reluctance torque to the torque produced by the PMs. The reluctance torque has its strongest contribution in the current-limited region below the base speed in which maximum torque is required. Because there is less magnet material, the back-emf at high speeds is reduced allowing the motor to have a wider CPSR. At high speeds, the additional torque can produce more power. Reluctance torque is generated when the stator field tries to pull ferromagnetic poles toward an equilibrium location. The current or voltage-phase angle, if not properly controlled, can oppose the PM torque.

2. Thanks to the reluctance contribution, higher-peak torques can be achieved at low speeds for the same current limit. This suggests that to improve the performance of a PM motor, one may reduce the magnitude of the PM energy in the rotor by reducing the PM thickness or area facing the gap, which increases the rotor's saliency ratio thereby compensating the loss in PM torque with an increased reluctance torque. In turn, the reduction in PM energy results in reduced rate of change of the backemf and magnetic-core losses as the speed increases. This increases the speed range, improves the efficiency, and reduces the motor's heat-removal load. This may play out as a cheaper motor with higher-power output, reduced back-emf, increased speed range, and increased efficiency.

3. Equations (24-30) in Chapter 2, which were derived from the equivalent circuit of a synchronousreluctance-assisted PM motor in Chapter 1, are applied to develop expressions for attainable voltage and current in terms of phase angles of either voltage or current. These expressions in turn are used to optimize power output and efficiency with algebraically-oriented methods using Mathematica in Chapter 2 and with numerically-oriented methods using LabVIEW in Chapter 3. The impact on the speed dependency of maximum-power output and maximum efficiency of a reluctance-assisted PM motor from changing the magnet fraction and magnetic strength depends on the control strategy used. Below base speed, we have investigated the impact of varying the magnet fraction and thickness by trading PM material for iron in an inset PM motor controlled with the optimal-current-phase angle or voltage-phase angle for each speed.

4. Most challenging is the characterization of magnetic saturation since, especially in the case of IPM motors, the magnetic flux paths vary significantly with the rotor's position relative to the rotating field generated by the stator. The use of lumped-parameter equations for modeling is appealing since it facilitates understanding, but it requires the determination of inductances, resistance, and flux linkages with the degree of detail appropriate for the simulation goals. It is best to have measured values of the lumped parameters. Next best is to obtain them by means of finite-element computations. Most often, though, they are obtained by means of calculations based on geometry, equivalent circuits, and adjustment factors as was the case in this study. 
5. The criteria defining optimum performance determines the parameters that will be optimized. The most common parameters for maximization are power output or efficiency and may flip from one to the other depending on the situation. For this study in which both power output and efficiency were maximized using steady-state expressions, the optimal-magnet fraction was minimized to 0.72 corresponding to a $130^{\circ} \mathrm{PM}$ pitch angle, and the magnet strength was minimized to $80 \%$ of maximum which will reduce magnet material cost without impacting the performance.

6. For automotive applications it seems appropriate to focus on efficiency where one should consider the speed-torque cycle for each particular application. We thus suggest that, in addition to the standard efficiency/torque maps, maximization of the efficiency over a set of standard-driving cycles should be a criterion to determine optimal configurations for reluctance-assisted PM motors.

Results of this study indicate that the reduction in PM torque due to reduced magnet fraction will be more than compensated by the reluctance torque resulting from the higher saliency ratio. It seems likely that the best overall performance will require saliency; consequently, we think the best motor will be a reluctance-assisted PM motor. Future research should explore the benefit that could be derived increasing saliency in the design of other types of PM motors such as fractional-slot motors with concentrated windings. 


\section{ACKNOWLEDGEMENTS}

The authors wish to acknowledge the expertise and assistance of J. M. Bailey in providing trigonometric closure to the derivations of the voltage and current transformations from a stationery-lab reference frame to a synchronously-rotating frame as we explored the relationship between the Blondel and Park transformations and how they related the current and voltage in the rotating frame to the current and voltage in the stationery frame. 


\section{REFERENCES}

1. N. Bianchi and T. Jahns, "Design, Analysis, and Control of Interior PM Synchronous Machines," Chapter 6 in Tutorial Course Notes, IEEE Industry Applications Society Annual Meeting, Seattle, Washington, October 3, 2004.

2. M. Kamiya, "Development of Traction Drive Motors for the Toyota Hybrid System," 2005 International Power Electronics Conference, Toki Messe in Niigata, Japan, April 4-8, 2005.

3. T. J. E. Miller, M. I. McGilp, and J. S. Hendershot, SPEED, software by SPEED Software Laboratory, University of Glasgow, distributed by MagSoft, received 2004.

4. O. I. Elgerd, Electric Energy Systems Theory: Introduction, McGraw-Hill Book Company, Chapter 4, 1971.

5. R. E. Doherty and C. A. Nickle, "Sunchronous Machines," pp. 912-942 in AIEE Trans., 45, 1926.

6. R. H. Park, "Two Reaction Theory of Synchronous Machines - Generalized Method of Analysis," pp. 716-727 in AIEE Trans., 48, 1929.

7. G. R. Slemon and X. Liu, "Core Losses in Permanent Magnet Motors," pp. 1653-1655 in IEEE Trans. on Magnetics, 16(5), September 1990. 
Internal

\section{DISTRIBUTION}
1. D. J. Adams
5. L. D. Marlino
2. J. M. Bailey
6. J. W. McKeever
3. M. A. Brown
7. M. Olszewski
4. K. P. Gambrell
8. Laboratory Records

\section{External}

9. T. Q. Duong, U.S. Department of Energy, EE-2G/Forrestal Building, 1000 Independence Avenue, S.W., Washington, D.C. 20585.

10. R. R. Fessler, BIZTEK Consulting, Inc., 820 Roslyn Place, Evanston, Illinois 60201-1724.

11. K. Fiegenschuh, Ford Motor Company, Scientific Research Laboratory, 2101 Village Road, MD2247, Dearborn, Michigan 48121.

12. V. Garg, Ford Motor Company, 15050 Commerce Drive, North, Dearborn, Michigan 481201261.

13. E. Jih, Ford Motor Company, Scientific Research Laboratory, 2101 Village Road, MD-1170, Rm. 2331, Dearborn, Michigan 48121.

14. W. C. Johnson, University of Tennessee-Knoxville, ECE Department, 414 Ferris Hall, 1508 Middle Drive, Knoxville, Tennessee 37996.

15. A. Lee, Daimler Chrysler, CIMS 484-08-06, 800 Chrysler Drive, Auburn Hills, Michigan 483262757.

16. F. Liang, Ford Motor Company, Scientific Research Laboratory, 2101 Village Road, MD1170, Rm. 2331/SRL, Dearborn, Michigan 48121.

17. M. W. Lloyd, Energetics, Inc., 7164 Columbia Gateway Drive, Columbia, Maryland 21046.

18. M. Mehall, Ford Motor Company, Scientific Research Laboratory, 2101 Village Road, MD-2247, Rm. 3317, Dearborn, Michigan 48124-2053.

19. N. Olds, United States Council for Automotive Research (USCAR), nolds@uscar.org

20. J. Rogers, Chemical and Environmental Sciences Laboratory, GM R\&D Center, 30500 Mound Road, Warren, Michigan 48090-9055.

21. S. A. Rogers, U.S. Department of Energy, EE-2G/Forrestal Building, 1000 Independence Avenue, S.W., Washington, D.C. 20585.

22. G. S. Smith, General Motors Advanced Technology Center, 3050 Lomita Boulevard, Torrance, California 90505.

23. E. J. Wall, U.S. Department of Energy, EE-2G/Forrestal Building, 1000 Independence Avenue, S.W., Washington, D.C. 20585.

24. B. Welchko, General Motors Advanced Technology Center, 3050 Lomita Boulevard, Torrance, California 90505.

25. P. G. Yoshida, U.S. Department of Energy, EE-2G/Forrestal Building, 1000 Independence Avenue, S.W., Washington, D.C. 20585. 